\title{
Roles of Urban Tree Canopy and Buildings in Urban Heat Island Effects: Parameterization and Preliminary Results
}

\author{
CHRISTOPHER P. LOUGHNER \\ Earth System Science Interdisciplinary Center, University of Maryland, College Park, College Park, \\ and NASA Goddard Space Flight Center, Greenbelt, Maryland \\ Dale J. Allen And DA-Lin Zhang \\ Department of Atmospheric and Oceanic Science, University of Maryland, College Park, College Park, Maryland \\ KENNETH E. PICKERING \\ NASA Goddard Space Flight Center, Greenbelt, Maryland \\ RUSSELL R. DICKERSON \\ Department of Atmospheric and Oceanic Science, University of Maryland, College Park, College Park, Maryland

\section{LAURA LANDRY} \\ Maryland Department of the Environment, Baltimore, Maryland
}

(Manuscript received 28 October 2011, in final form 16 April 2012)

\begin{abstract}
Urban heat island (UHI) effects can strengthen heat waves and air pollution episodes. In this study, the dampening impact of urban trees on the UHI during an extreme heat wave in the Washington, D.C., and Baltimore, Maryland, metropolitan area is examined by incorporating trees, soil, and grass into the coupled Weather Research and Forecasting model and an urban canopy model (WRF-UCM). By parameterizing the effects of these natural surfaces alongside roadways and buildings, the modified WRF-UCM is used to investigate how urban trees, soil, and grass dampen the UHI. The modified model was run with $50 \%$ tree cover over urban roads and a $10 \%$ decrease in the width of urban streets to make space for soil and grass alongside the roads and buildings. Results show that, averaged over all urban areas, the added vegetation decreases surface air temperature in urban street canyons by $4.1 \mathrm{~K}$ and road-surface and building-wall temperatures by 15.4 and $8.9 \mathrm{~K}$, respectively, as a result of tree shading and evapotranspiration. These temperature changes propagate downwind and alter the temperature gradient associated with the Chesapeake Bay breeze and, therefore, alter the strength of the bay breeze. The impact of building height on the UHI shows that decreasing commercial building heights by $8 \mathrm{~m}$ and residential building heights by $2.5 \mathrm{~m}$ results in up to 0.4-K higher daytime surface and near-surface air temperatures because of less building shading and up to 1.2-K lower nighttime temperatures because of less longwave radiative trapping in urban street canyons.
\end{abstract}

\section{Introduction}

Urbanization can alter local climate and form an urban heat island (UHI; Landsberg 1981). Altering land use by creating impervious urban surfaces causes increased runoff, decreased evapotranspiration, increased

Corresponding author address: Dr. Christopher P. Loughner, Goddard Space Flight Center, Code 614, Greenbelt, MD 20771.

E-mail: christopher.p.loughner@nasa.gov solar radiation absorption, additional release of anthropogenic heat, and changes in surface friction, which results in changes in near-surface air temperature, humidity, wind speeds, low-level convergence/divergence, convection, and precipitation (e.g., Oke and Cleugh 1987; Bornstein and Lin 2000; Arnfield 2003). Previous studies show that UHIs strengthen as city size and building density increase (Oke 1973; Landsberg 1981; Atkinson 2003; Imhoff et al. 2010). In addition, a recent study reveals that upstream urbanization can magnify 
UHI effects under the favorable influence of larger-scale flow (Zhang et al. 2009, 2011). Therefore, a smaller city with upstream urbanization can have a larger UHI than a larger city with no upstream urbanization (Zhang et al. 2009).

A UHI can have ill effects on human health. The UHI can amplify summertime heat waves, leading to heat stress (Kunkel et al. 1996). The UHI can also aggravate air pollution. Air quality model results show air pollution worsens as temperature increases (Weaver et al. 2009; Banta et al. 1998; Cheng and Byun 2008; Jacob and Winner 2009), and observations confirm a correlation between high temperature and events with high air pollution (Bloomer et al. 2009, 2010; Tai et al. 2010).

Urban trees have the potential to dampen the UHI and decrease near-surface temperatures through direct shading and evaporative cooling. Observations show temperatures over a grassy surface were $0.7-1.3 \mathrm{~K}$ cooler under urban trees than adjacent areas with no tree cover (Souch and Souch 1993). Similar measurements revealed temperatures to be $2.2-3.3 \mathrm{~K}$ cooler under mature trees in a suburban neighborhood than in new developments with no trees (McGinn 1982). Planting trees near buildings can reduce summertime building-surface temperatures through shading and evapotranspiration, which can in turn reduce energy use for cooling building interiors (Heisler 1986) and therefore emissions from power plants. Specifically, trees planted near a building reduce building heat gain by 1) shading solar radiation incident on the building, 2) shading nearby surfaces that radiate heat toward the building, 3) reducing the outside air infiltration rate by lowering ambient wind speeds, and 4) lowering ambient temperatures through evapotranspiration (Akbari 2002). A summertime energy-use study in which eight 6-m-tall and eight 2.4-m-tall trees were planted around one house and then moved to another house showed that shading by these trees decreased summertime energy demand by as much as 30\% (Akbari et al. 1997).

Planting trees in urban areas can also improve air quality by decreasing air temperatures and increasing the removal rate of pollutants from the atmosphere. A decrease in air temperature lowers the temperaturedependent emission rate of volatile organic compounds (VOCs) from vegetation and temperature-dependent chemical reaction rates that produce tropospheric ozone (Taha 1995). Although increasing the amount of trees increases the amount of vegetation that emits VOCs that react with nitrogen oxides to form ozone, trees also filter air pollution. Most gaseous air pollutants that are removed by trees are taken up by leaf stomata, but some are removed by the surface of trees (Nowak et al. 2006).
Some particles that come into contact with trees are absorbed into the trees, but most remain on the surface of trees until they are resuspended into the atmosphere or are transported to the surface by precipitation or falling leaves or branches (Nowak et al. 2006). A regional meteorological and air quality modeling study revealed that planting trees that emit low amounts of VOCs decreased tropospheric ozone concentrations whereas planting trees that emit large amounts of VOCs degraded air quality in Los Angeles, California (Taha 1995). This study did not account for further reductions in ozone concentrations due to changes in energy demand and anthropogenic emissions from planting additional trees. A further modeling study shows that planting 20 million trees in the Los Angeles air basin reduces the mass of ozone in the mixed layer by $4.5 \%$ because of increased deposition of ozone and nitrogen dioxide (Taha et al. 1997).

A UHI in a coastal region may have the potential to alter a sea, lake, or bay breeze, thereby affecting air quality. A summertime sea breeze is driven by the temperature gradient between the warm land and cool water. Increasing or decreasing land surface temperature through urbanization or planting urban trees, respectively, will alter the temperature gradient and therefore modify the strength of the sea breeze. Previous studies have shown that a sea-breeze circulation can exacerbate air pollution levels (Boucouvala and Bornstein 2003; Evtyugina et al. 2006; Loughner et al. 2011). In Houston, high ozone episodes begin when the large-scale flow is offshore before a bay breeze develops (Banta et al. 2005; Darby 2005). As the bay breeze begins to strengthen, stagnant conditions develop, allowing ozone and its precursors to accumulate before being advected farther onshore as the bay breeze increases in intensity later in the afternoon (Banta et al. 2005; Darby 2005).

With the rapid increases in computing power in recent years, there have been a growing number of higherresolution model simulations. Many studies show benefits of using high-resolution mesoscale models to resolve frontal structures, orographical flows, and vertical circulations induced by surface inhomogeneities [see Mass et al. (2002) for a review]. For urban settings at finescales (horizontal grid spacing less than $1 \mathrm{~km}$ ), urban canopy models are used to simulate the meteorological conditions in the complex urban environment consisting of streets, buildings, and vegetation. Currently, the Weather Research and Forecasting (WRF) model (Skamarock et al. 2008) can be run coupled with the "Noah" land surface model and an urban canopy model (Kusaka et al. 2001) (WRF-UCM). This urban canopy model does not include soil, grass, or trees in urban street canyons, however. Lee and Park (2008) developed a vegetated urban canopy 
model and found that canyon vegetation has a large influence on surface temperatures and sensible and latent heat fluxes.

In the present study, the effects of soil, grass, and trees in urban street canyons are incorporated into version 3.1.1 of the WRF-UCM to examine how urban trees dampen the UHI and how sensitive the UHI is to urban building height. These objectives are accomplished by performing simulations down to a horizontal grid spacing of $0.5 \mathrm{~km}$ with a modified version of the Advanced Research WRF-UCM in which urban trees, soil, and grass are incorporated, following closely the work of Lee and Park (2008). The simulations cover the WashingtonBaltimore metropolitan areas from 1200 UTC 7 July to 1200 UTC 10 July 2007. High air pollution was observed in the region under hot, sunny, stagnant conditions. A cold front passed through the area on 6 July 2007, followed by a short-wave trough approaching the Mid-Atlantic region (Zhang et al. 2011). The Baltimore, Maryland, UHI exhibited a 2-m temperature of $37.5^{\circ} \mathrm{C}$, and downwind of Baltimore near-surface 8-h maximum ozone mixing ratios reached $125 \mathrm{ppb}$ (the current air quality standard is $75 \mathrm{ppb}$ ) on 9 July. Previous work examining this modeling scenario explored the impact of upstream urbanization on the UHI (Zhang et al. 2009, 2011), characterized the air pollution event (Yegorova et al. 2011), and investigated the effects of fair-weather cumulus clouds and the Chesapeake Bay breeze on air quality (Loughner et al. 2011).

\section{Model description and modification}

In this section, we will describe the basic configuration of the coupled WRF-UCM model and then show how the tree effects are incorporated into the coupled model, followed by the description of sensitivityexperiment designs to study the impact of trees on UHI.

\section{a. Model configuration}

In the coupled Advanced Research WRF-UCM, the Noah land surface model calculates soil moisture and temperature, skin temperature, canopy water content, and the energy and water flux terms in the surface and water energy balance equations (Chen and Dudhia 2001) and the UCM improves the parameterization of physical processes involved in the exchange of heat, momentum, and water vapor in urban environments by including shadowing from buildings, reflection of shortwave and longwave radiation, wind profile information in the canopy layer, and a multilayer heat transfer equation for roof, wall, and road surfaces (Kusaka and Kimura 2004).
The WRF-UCM includes three categories of urban surfaces: commercial/industrial/transportation, high-intensity residential, and low-intensity residential. Each urban category consists of fractional coverage of urban land occupied by buildings and roads, with the remaining fraction as undeveloped land. Urban fraction is set to $95 \%, 90 \%$, and $50 \%$ for grid cells labeled commercial/industrial/transportation, high-intensity residential, and low-intensity residential, respectively, for the model simulations described herein. The remaining land in grid cells classified as urban is considered to be undeveloped and is classified as U.S. Geological Survey (USGS) land-use type "cropland/grassland mosaic." Surface heat and moisture fluxes are calculated in the UCM for urban streets and buildings and in the Noah land surface model for undeveloped urban land.

The coupled model is run at 13.5-, 4.5-, 1.5-, and $0.5-\mathrm{km}$ horizontal grid spacings with $x, y$ dimensions of $181 \times 151,244 \times 196,280 \times 247$, and $349 \times 349$ grid cells, respectively (see Fig. 1 for the model domains). All of the domains use 32 layers in the vertical direction with 20 layers in the lowest $2 \mathrm{~km}$. The North American Regional Reanalysis is used for the model initial and outermost lateral boundary conditions. The three categories of urban surfaces are defined by the U.S. Environmental Protection Agency's National Land Cover Dataset for 2001. The urban areas in the $0.5-\mathrm{km}$ domain are displayed in Fig. 2. The model physics schemes used include 1) a double-moment six-class microphysics scheme (Lim and Hong 2010), 2) the Mellor-YamadaJanjić boundary layer parameterization (Janjić 1994), 3 ) the Noah land surface model (Chen and Dudhia 2001), and 4) an ensemble cumulus parameterization that advances the Grell-Devenyi scheme (Grell and Devenyi 2002) to allow subsidence in neighboring grid cells (Skamarock et al. 2008). The cumulus parameterization is only used for the $4.5-$ and $13.5-\mathrm{km}$ domains.

\section{b. Including trees in the UCM}

The WRF-UCM was modified to investigate how urban trees impact the UHI effects. The WRF-UCM was tailored to include grass, soil, and trees in urban street canyons and trees in undeveloped land in urban grid cells. Urban vegetation coverage is described in Table 1. The urban tree leaf area index (LAI) is set to 3.31, the same as USGS land-use type "deciduous broadleaf forest" and in line with favorable urban trees found in the Mid-Atlantic region. Averaged LAIs by individual tree species from a tree survey in New York City, New York, range from 0.68 for honey locust trees to 10.07 for northern white cedar trees (TreesNY and CENYC 2002). Ideally, urban trees must be durable, must be able 


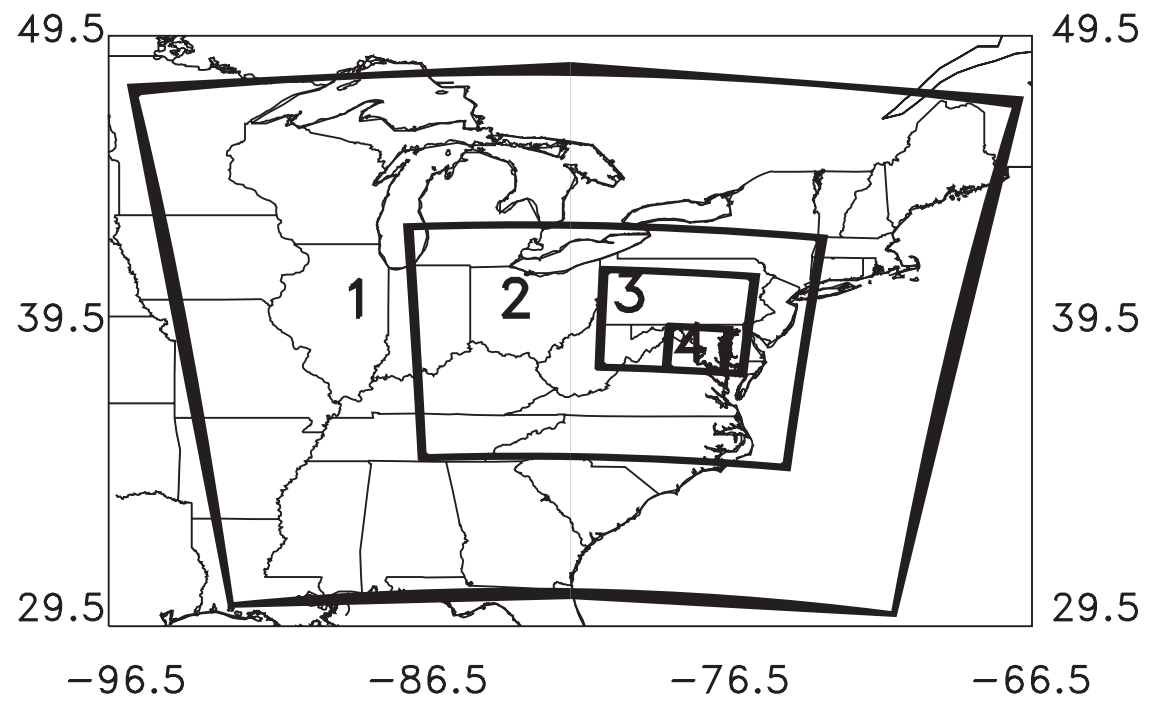

FIG. 1. Location of model domains 1,2,3, and 4, which have horizontal grid spacings of 13.5, 4.5, 1.5 , and $0.5 \mathrm{~km}$, respectively.

to thrive in an urban environment, must be low biogenic VOC emitters, and must have a large LAI to cause maximum shading, latent heat exchange, and pollutant deposition. A list of urban tree species from the U.S. Department of Agriculture Forest Service (Chicago Botanic Garden 2011) was referenced to find trees that are suitable to live in an urban environment. Biogenic emissions of tree species from the Biogenic Emissions Inventory System (Vukovich and Pierce 2002) were referenced to find low-VOC emitters. LAIs from a New York City tree survey (TreesNY and CENYC 2002) were referenced to determine which trees have a large LAI. It was determined that ash and elm trees are preferred urban trees for the Washington and Baltimore metropolitan areas. Observed average LAI in New York City for ash and elm trees is 4.11 and 3.12, respectively (TreesNY and CENYC 2002). Urban-canyon tree height is set to $10 \mathrm{~m}$, which is in line with observed ash and elm tree heights in New York City. Average and maximum tree heights in New York City are 11.84 and $19.50 \mathrm{~m}$, respectively, for ash trees and 11.58 and $27.40 \mathrm{~m}$ for elm trees (TreesNY and CENYC 2002).

To increase the percentage tree cover in the undeveloped land from $0 \%$ to $50 \%$, the undeveloped land is reclassified from USGS land-use type cropland/ grassland mosaic to USGS land-use type "cropland/ woodland mosaic." A 50\% tree cover over undeveloped land and urban streets results in $26.25 \%, 27.5 \%$, and $37.5 \%$ tree cover over commercial/industrial/transportation, highintensity residential, and low-intensity residential urban areas, respectively. Tree canopy cover in urban and metropolitan areas in the United States averages 27\% and
$33 \%$, respectively (Dwyer and Nowak 2000). Surface heat and moisture fluxes are calculated with the Noah land surface model for undeveloped urban land and with the UCM for the urban buildings and street canyons.

The UCM was modified to account for fractional coverage of grass, soil, and tree canopies in the street canyons, including the increased momentum drag due to the tree canopy; the transmissivity of shortwave and longwave radiation through the tree canopy; tree shading on building roofs, building walls, and the ground; and additional shortwave radiative, longwave radiative, latent heat, and sensible heat fluxes due to the added trees, soil, and grass. The UCM was modified by blending a vegetated urban canopy model (Lee and Park 2008) with a single-layer urban canopy model (Kusaka et al. 2001; Kusaka and Kimura 2004), which is already coupled inside the WRF modeling system. Details on the blending of these two models are described in the appendix.

\section{c. Experimental design}

Three different WRF-UCM simulations were performed to achieve the above-mentioned objectives: 1 ) a base case; 2) a run with urban soil, grass, and trees; and 3) a scenario with shorter buildings. Hereinafter, these simulations are referred to as "no trees," "trees," and "no trees/shorter buildings." Urban fraction and building and canyon dimensions for the three model simulations and three urban categories are displayed in Table 2. The no trees/shorter buildings simulation is performed to test the sensitivity of the UHI effects to building height. 


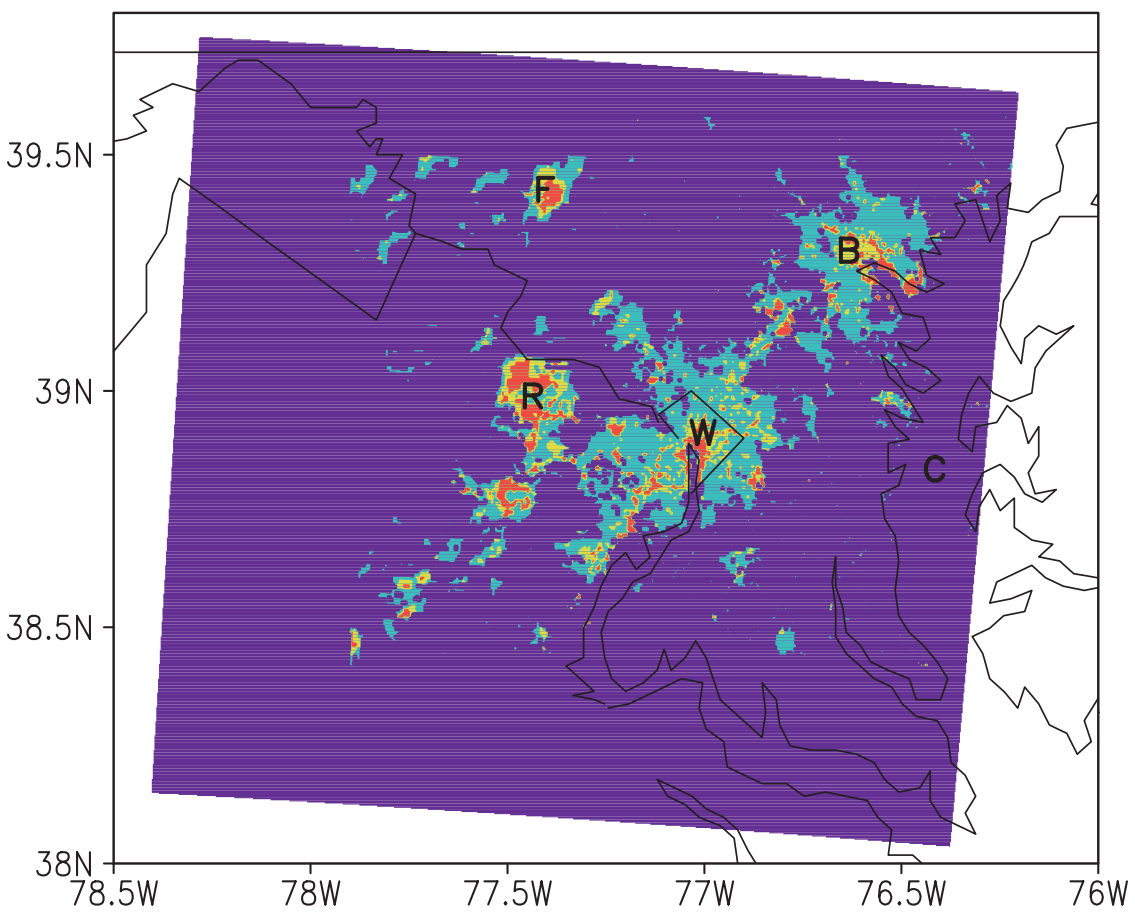

FIG. 2. Urban land use in the 0.5 -km-horizontal-resolution domain, where red, yellow, and cyan represent commercial/industrial/transportation, high-intensity residential, and lowintensity residential, respectively. The letters F, R, B, and W denote the cities of Frederick, MD; Reston, VA; Baltimore; and Washington. The letter C shows the location of the Chesapeake Bay.

\section{Sensitivity simulations}

Three nested-grid simulations (i.e., no trees, trees, and no trees/shorter buildings) with the finest grid spacing of $0.5 \mathrm{~km}$ are analyzed alongside observations to investigate the role of urban trees and building heights on the UHI. Averaged over 23 measurement sites within the $0.5-\mathrm{km}$-resolution domain, the near-surface (at height $z=2 \mathrm{~m}$ ) temperatures for all three simulations are compared with temperature and wind velocity observations from the National Weather Service and the Maryland Department of the Environment. The observational sites include urban sites and sites that are downwind and upwind of urban areas. The model sites include the observational sites but are averages over a $0.5-\mathrm{km}$ domain that may include a mixture of urban streets, buildings, and undeveloped land. Statistics of 2-m temperature comparisons between the model simulations and observations show that all three model simulations agree reasonably well with the observations (Table 3). There are noticeable differences among the simulations, however. The trees simulation consistently has lower surface temperatures than the no-trees simulation because of increased evapotranspiration and shading of roads and buildings. At the measurement sites, the surface temperature of the trees simulation is on average $0.3 \mathrm{~K}$ cooler than the no-trees simulation between 1200 UTC 8 July and 1200 UTC 10 July. The no

TABLE 1. Specification of urban-canyon grass/soil fraction, urban-canyon tree canopy fraction, undeveloped-land tree canopy fraction, and tree cover fraction over total grid cells for the three urban categories [low-intensity residential (LI), high-intensity residential (HI), and commercial/industrial/transportation (C)] and the three simulations [no trees (NT), trees (T), and no trees/shorter buildings (NTSB)].

\begin{tabular}{|c|c|c|c|c|c|c|c|c|c|c|c|c|}
\hline & \multicolumn{3}{|c|}{$\begin{array}{c}\text { Urban-canyon grass/ } \\
\text { soil fraction }\end{array}$} & \multicolumn{3}{|c|}{$\begin{array}{l}\text { Urban-canyon tree } \\
\text { canopy fraction }\end{array}$} & \multicolumn{3}{|c|}{$\begin{array}{l}\text { Undeveloped-land } \\
\text { tree canopy fraction }\end{array}$} & \multicolumn{3}{|c|}{$\begin{array}{l}\text { Tree cover of } \\
\text { total grid }(\%)\end{array}$} \\
\hline & LI & HI & $\mathrm{C}$ & LI & $\mathrm{HI}$ & $\mathrm{C}$ & LI & $\mathrm{HI}$ & $\mathrm{C}$ & LI & HI & $\mathrm{C}$ \\
\hline NT & 0 & 0 & 0 & 0 & 0 & 0 & 0 & 0 & 0 & 0 & 0 & 0 \\
\hline $\mathrm{T}$ & 0.1 & 0.1 & 0.1 & 0.5 & 0.5 & 0.5 & 0.5 & 0.5 & 0.5 & 37.5 & 27.5 & 26.25 \\
\hline NTSB & 0 & 0 & 0 & 0 & 0 & 0 & 0 & 0 & 0 & 0 & 0 & 0 \\
\hline
\end{tabular}


TABLE 2. Specification of urban fraction, building height and depth, and urban-canyon width for the three urban categories and three simulations.

\begin{tabular}{|c|c|c|c|c|c|c|c|c|c|c|c|c|}
\hline & \multicolumn{3}{|c|}{ Urban fraction } & \multicolumn{3}{|c|}{ Building height (m) } & \multicolumn{3}{|c|}{ Building depth (m) } & \multicolumn{3}{|c|}{ Urban-canyon width (m) } \\
\hline & LI & $\mathrm{HI}$ & $\mathrm{C}$ & LI & $\mathrm{HI}$ & $\mathrm{C}$ & $\mathrm{LI}$ & $\mathrm{HI}$ & $\mathrm{C}$ & $\mathrm{LI}$ & $\mathrm{HI}$ & $\mathrm{C}$ \\
\hline NT & 0.5 & 0.9 & 0.95 & 7.5 & 10 & 20 & 8.3 & 9.4 & 10 & 8.3 & 9.4 & 10 \\
\hline $\mathrm{T}$ & 0.5 & 0.9 & 0.95 & 7.5 & 10 & 20 & 8.3 & 9.4 & 10 & 8.3 & 9.4 & 10 \\
\hline NTSB & 0.5 & 0.9 & 0.95 & 5 & 7.5 & 12 & 8.3 & 9.4 & 10 & 8.3 & 9.4 & 10 \\
\hline
\end{tabular}

trees/shorter buildings simulation has higher daytime temperatures but lower nighttime temperatures than the no-trees simulation. Averaged over all of the measurement sites, maximum differences between the no trees/ shorter buildings and no-trees simulations peaked at $0.4 \mathrm{~K}$ during the day and $1.2 \mathrm{~K}$ during the night. Shorter buildings produce fewer shadows, thereby allowing more solar radiation to heat the building walls and roads. On the other hand, street canyons with shorter buildings trap less longwave radiation emitted from the surfaces, allowing the surface to cool more quickly during the nighttime.

At 2000 UTC (i.e., 1500 LST) 9 July 2007, the Chesapeake Bay breeze's convergence zone was over Baltimore (Fig. 3), and at 2300 UTC (i.e., 1800 LST) it was between Washington and Baltimore (Fig. 4). The no trees/shorter buildings simulation is slightly warmer than the no-trees simulation. The maximum 2-m temperature difference between the no trees/shorter buildings and notrees simulations in Washington is $0.6 \mathrm{~K}$ at $2000 \mathrm{UTC}$ and $0.4 \mathrm{~K}$ at 2300 UTC 9 July (not shown). Even though this difference is small, it can be seen from Figs. 3 and 4 that the spatial extent of the highest temperatures in the region is largest in the no trees/shorter buildings simulation, followed by the no-trees and then the trees simulations.

The maximum difference between the no-trees- and trees-simulated 2-m temperature is 0.8 and $1.2 \mathrm{~K}$ at 2000 and $2300 \mathrm{UTC}$, respectively, in Washington and $1.9 \mathrm{~K}$ at 2000 and 2300 UTC in Baltimore. Differences in 2-m temperature between the no-trees and the trees simulations at 2000 (Fig. 5a) and 2300 UTC (Fig. 5b) show that the impact of planting trees in all urban areas in the domain is largest in Baltimore.

Urban trees are seen to affect the strength of the Chesapeake Bay breeze. Figures 5a and 5b show the change in temperature associated with trees at 2000 and 2300 UTC, respectively. The most striking feature is a thin line of warmer temperatures in the trees simulation than in the no-trees simulation running north-south between Washington and Baltimore. Northwest of Baltimore, this thin line switches sign, indicating cooler temperatures in the trees simulation. At 2300 UTC, the thin line shows temperatures of up to $2 \mathrm{~K}$ warmer in the trees simulation than in the no-trees simulation east and northeast of Washington but temperatures that are $2 \mathrm{~K}$ cooler northwest of Baltimore (Fig. 5b). This thin line is attributable to differences in the positioning of the Chesapeake Bay-breeze convergence zone. High temperatures resulting from the Washington UHI propagating downwind near the coastline of the Chesapeake Bay strengthen the temperature gradient along the Chesapeake Bay coastline and therefore strengthen the bay breeze. The addition of urban trees dampens the urban heat island, causing a weaker temperature gradient along the coastline and a weaker bay breeze that does not penetrate as far inland downwind of Washington. So, the thin line of warmer temperatures in the trees simulation shown in Figs. 5a, 5b, and 5d to the east and northeast of Washington can be attributed to a weaker bay breeze that does not push the cooler air originating over the water as far inland. On the other hand, once a bay breeze penetrates inland past an urban area with cool air originating over the water moving over the city, the UHI warms this cool air, which is being transported to the bay-breeze front. This warming of the cool air causes a weaker temperature gradient along the bay-breeze front, lessening the inland penetration of the bay breeze. The addition of trees to a coastal city, however, causes dampening of the UHI so that the amount of warming of the cool air moving over the city toward the inland bay-breeze front by the UHI is reduced. Therefore, for conditions in which a bay breeze penetrates past a coastal city, the addition of trees results in a stronger bay breeze that penetrates farther inland. So, the thin line of cooler temperatures in the trees simulation shown in Figs. 5a, 5b, and 5c to the northwest of Baltimore can be attributed to a stronger bay breeze that penetrates farther inland. As mentioned previously,

TABLE 3. Mean absolute error (MAE), mean bias error (MBE), and root-mean-square error (RMSE) of 2-m temperature from 0000 UTC 8 Jul through 1200 UTC 10 Jul 2007 for the three simulations calculated at 23 measurement sites within the $0.5-\mathrm{km}$ horizontal domain. The observational locations include sites located in, downwind, and upwind of urban areas.

\begin{tabular}{lccc}
\hline & MAE & MBE & RMSE \\
\hline NT & 1.75 & 0.50 & 2.23 \\
T & 1.74 & 0.24 & 2.25 \\
NTSB & 1.65 & 0.41 & 2.10 \\
\hline
\end{tabular}


a) Observations

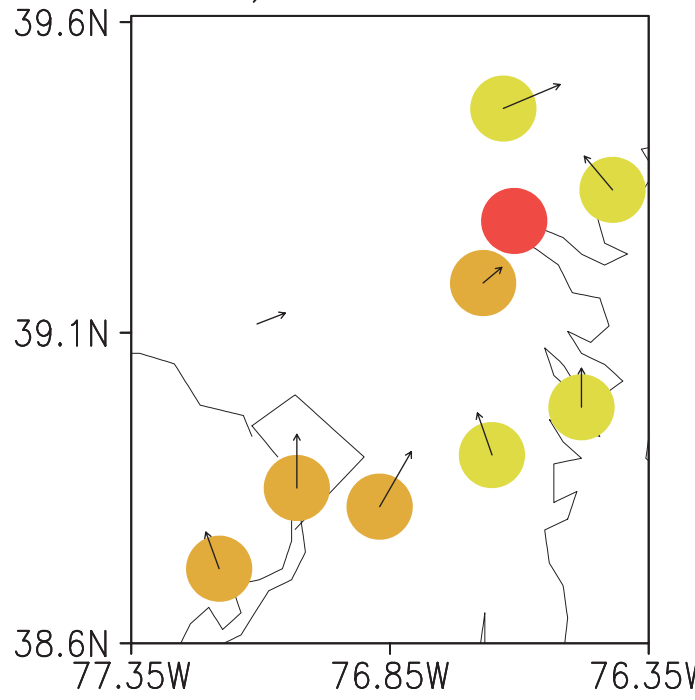

c) Trees

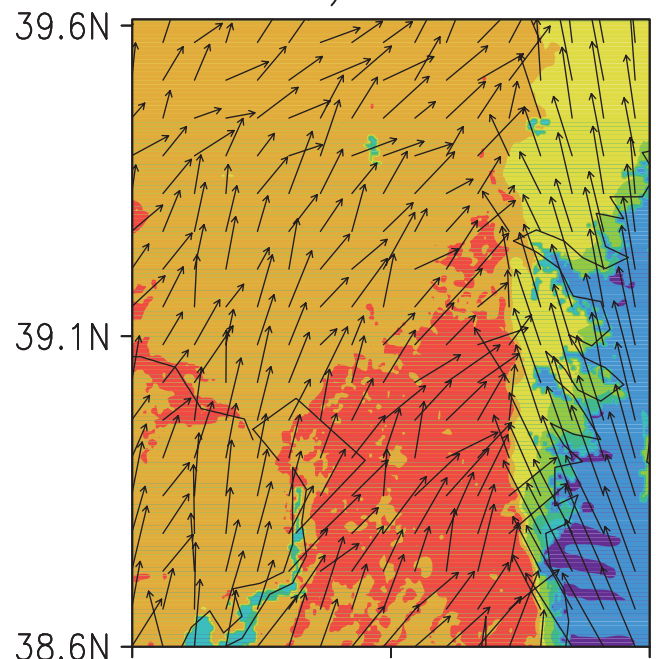

b) No Trees Shorter Buildings

$39.6 \mathrm{~N}$

$39.1 \mathrm{~N}$

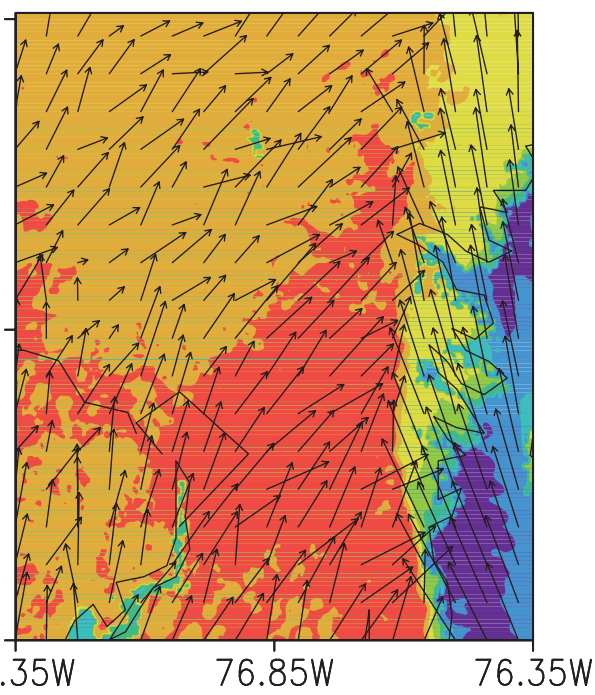

d) No Trees

$39.6 \mathrm{~N}$

$38.6 \mathrm{~N}$

$39.1 \mathrm{~N}$

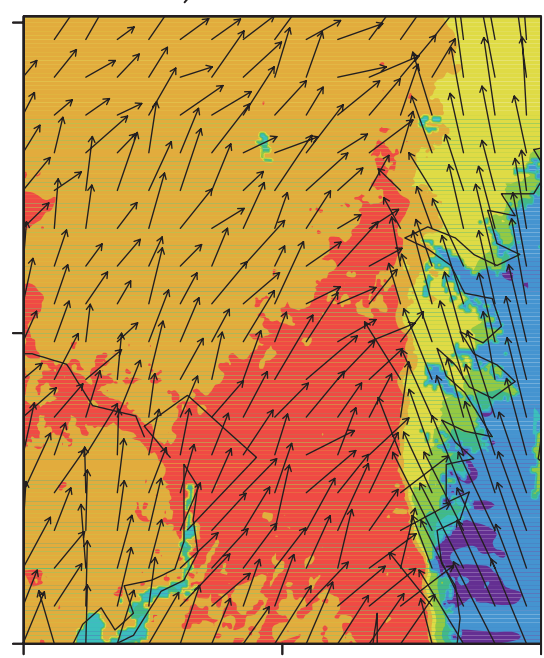

FIG. 3. Observed and simulated 2-m temperature (color shading) and 10-m wind speed (arrows) at a horizontal resolution of $0.5 \mathrm{~km}$ at $2000 \mathrm{UTC}$ (i.e., $1500 \mathrm{LST}) 9 \mathrm{Jul} 2007$.

the impact of planting trees in all urban areas in the domain is larger in Baltimore than in Washington. Since the bay breeze is stronger over and downwind of Baltimore in the trees simulation than in the no-trees simulation after the bay-breeze convergence zone passes through Baltimore, more air originating over the cool surface waters is transported to Baltimore. So, cooler temperatures over Baltimore in the trees simulation than in the no-trees simulation are attributable to a stronger bay breeze transporting cool air over Baltimore at a faster rate.
There are significant urban temperature differences on the subgrid scale. Figure 6 shows building-roof-, building-wall-, and road-surface temperatures as well as street-canyon air temperature averaged over all urban buildings, roads, and street canyons for the three simulations. The roof-surface temperatures vary little among the three simulations because the roofs for both the notrees and no trees/shorter buildings simulations are not shaded and only the low-intensity-residential roofs in the trees simulations are partially shaded at low solar 
a) Observations

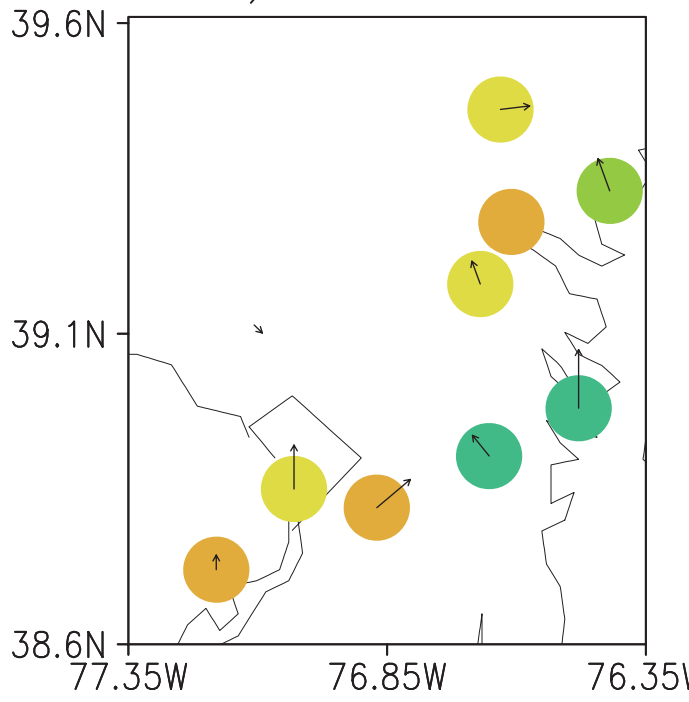

c) Trees

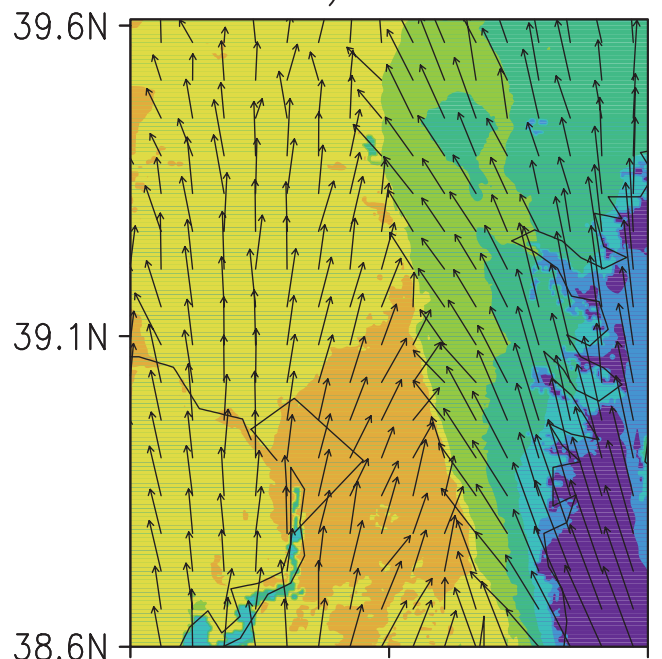

b) No Trees Shorter Buildings

$38.6 \mathrm{~N}$

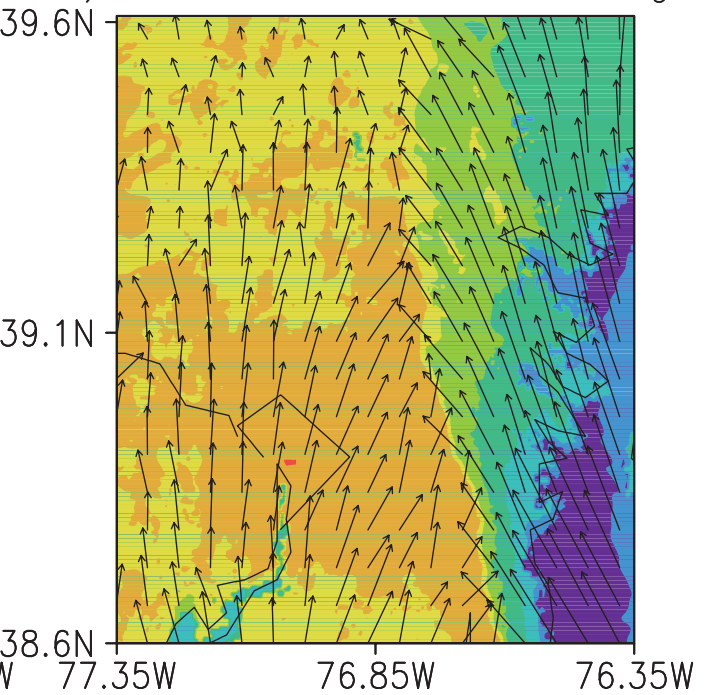

d) No Trees

$39.6 \mathrm{~N}$

$39.1 \mathrm{~N}$

$38.6 \mathrm{~N}$

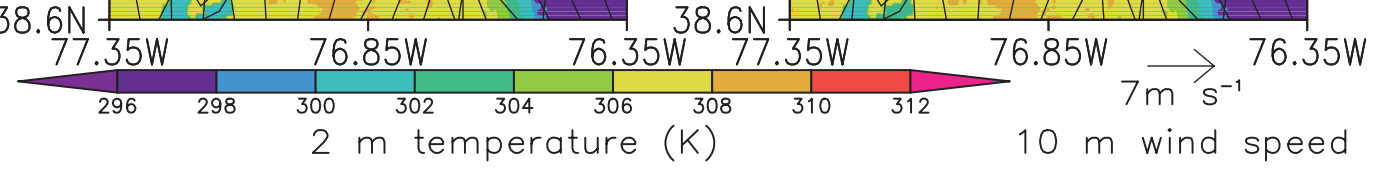

FIG. 4. As in Fig. 3, but at 2300 UTC (i.e., 1800 LST).

zenith angles. The no trees/shorter buildings simulation's maximum daytime building-wall- and road-surface temperatures and maximum canyon air temperature are 1.9, 2.4 , and $1.5 \mathrm{~K}$ greater, respectively, than the no-trees simulation's temperatures on 9 July because of more shading from the buildings. On the other hand, the no trees/shorter buildings simulation's minimum nighttime building-wall- and road-surface temperatures and minimum canyon air temperature are $0.4,0.6$, and $0.6 \mathrm{~K}$ lower, respectively, than in the no-trees simulation's temperatures between sunset on 8 July and sunrise on
9 July as a result of less longwave radiative trapping in the urban canyon. The trees simulation's maximum building-wall- and road-surface temperatures and maximum canyon air temperature are 8.9, 15.4, and $4.1 \mathrm{~K}$ lower, respectively, than the no-trees simulation's temperatures on 9 July because of tree shading and evapotranspiration. The trees simulation's minimum wall- and road-surface temperatures and canyon air temperature are 3.1,3.2, and $2.5 \mathrm{~K}$ lower, respectively, than the no-trees simulation's temperatures during the night of 8 July. 


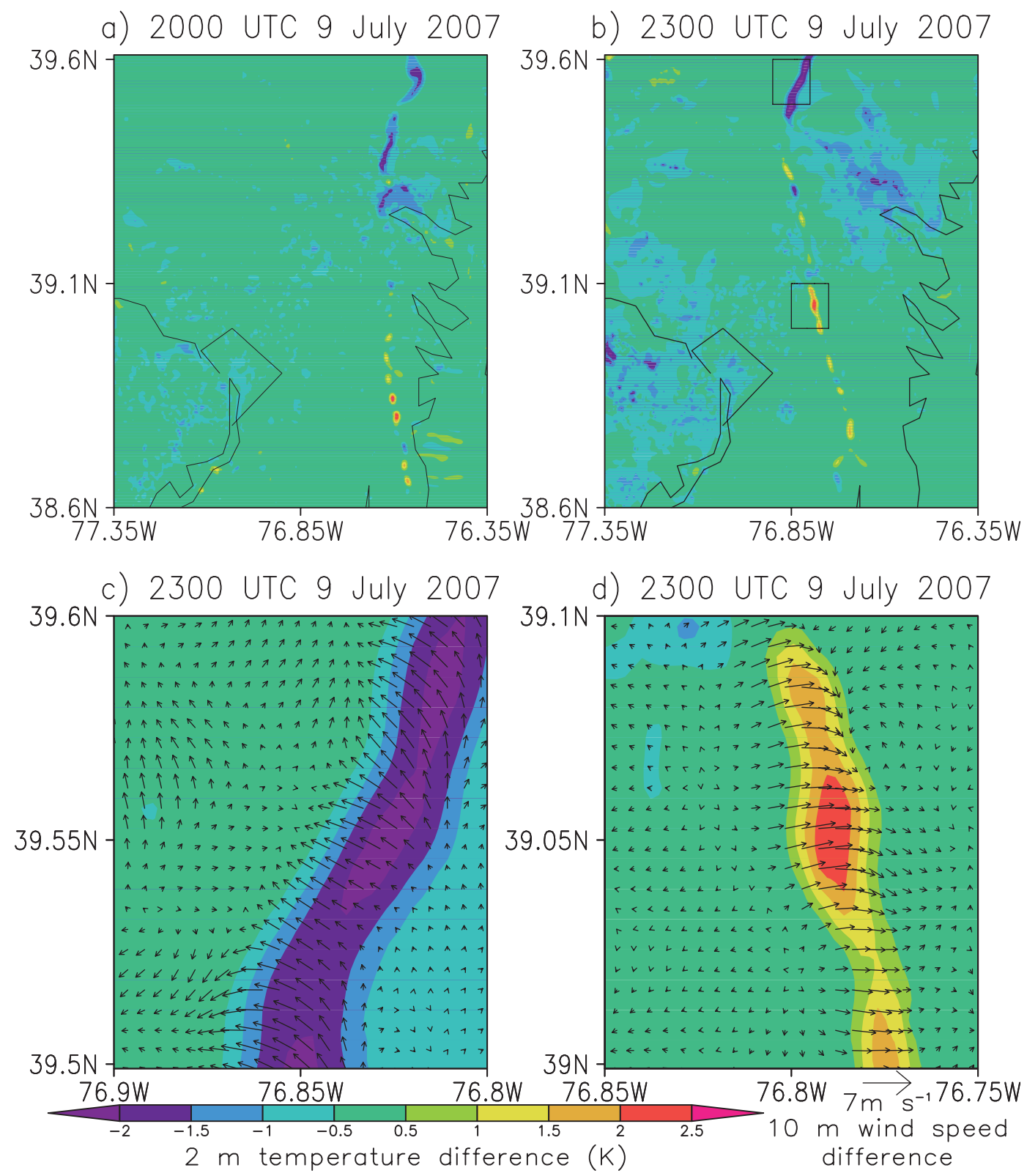

FIG. 5. Difference in trees minus no-trees 2-m temperature simulations with a horizontal resolution of $0.5 \mathrm{~km}$ at (a) 2000 UTC (i.e., 1500 LST) and (b) 2300 UTC (i.e., 1800 LST) 9 Jul 2007. The areas in the rectangles in (b) that are northwest of Baltimore and between Washington and Baltimore are shown in detail in (c) and (d), respectively, for 2300 UTC, with 10-m wind velocities added.

\section{Concluding remarks}

In this study, the roles of urban trees and building height in UHI effects are investigated by performing two simulations with a modified version of the WRFUCM: one with the inclusion of the parameterized effects of urban trees, soil, and grass and the other without those effects. Results show that urban areas with shorter buildings have a larger diurnal cycle. Shorter urban buildings cause higher surface and near-surface air temperatures during the daytime because of less building shading and cause lower temperatures at night as a result of less longwave radiative trapping in urban street canyons. In the model simulations, decreasing building size causes maximum daytime urban-canyon air temperature to increase by $1.5 \mathrm{~K}$ and minimum nighttime urban-canyon air temperature to decrease by $0.6 \mathrm{~K}$. Urban trees result in lower surface and near-surface 

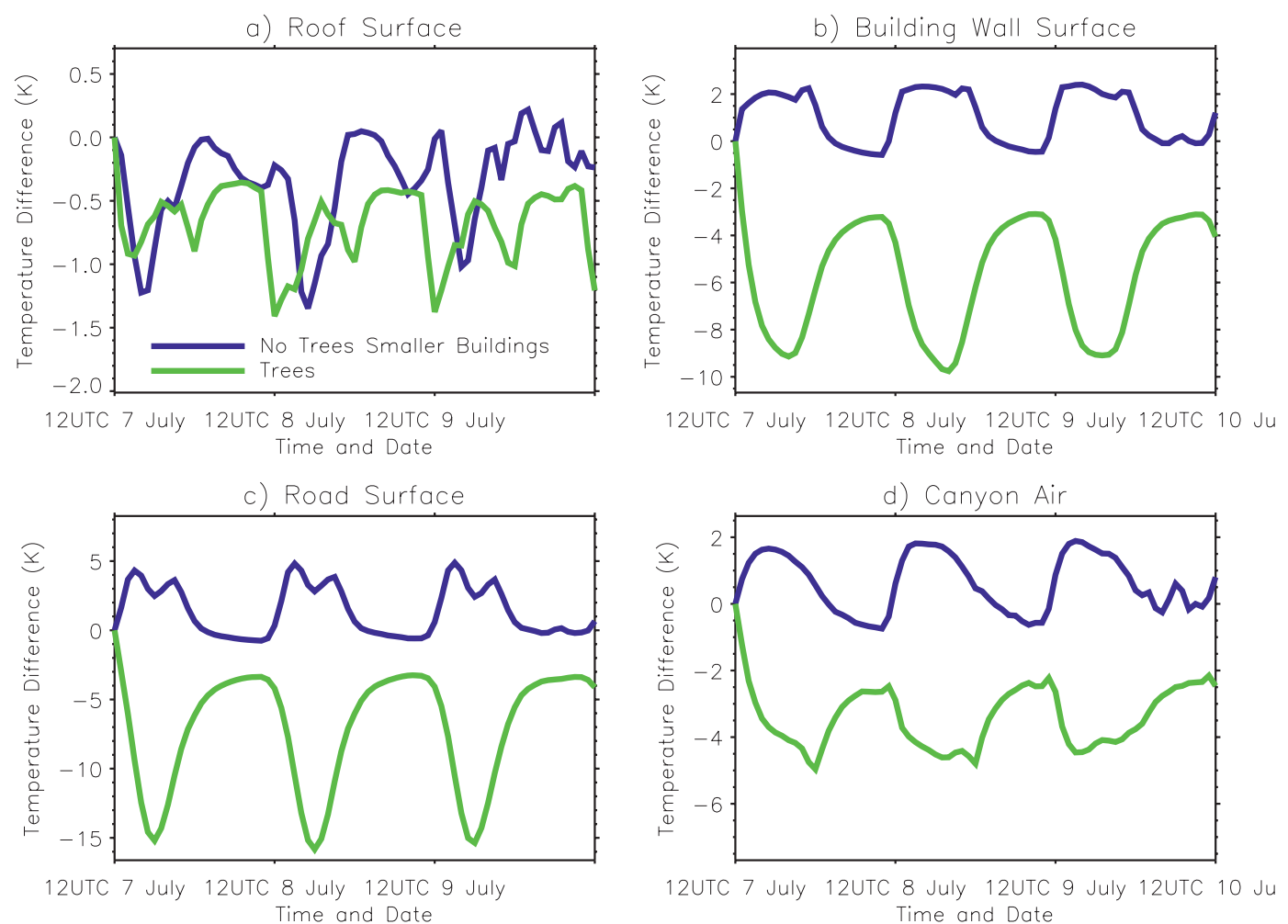

FIG. 6. Time series of no trees/shorter buildings minus no trees (blue), and trees minus no trees (green) simulated subgrid (a) roof-, (b) building-wall-, and (c) road-surface temperatures and (d) canyon air temperature with a horizontal resolution of $0.5 \mathrm{~km}$ averaged over all urban land-use categories from the 3-day simulations between 1200 UTC 7 Jul and 1200 UTC 10 Jul 2007.

air temperatures because of tree shading and evapotranspiration. The addition of trees in the simulations causes maximum daytime and minimum nighttime urbancanyon air temperatures to decrease by 4.1 and $2.5 \mathrm{~K}$, respectively. Future investigations will look into how these temperature differences that result from varying building height and urban vegetation cover influence emissions, climate, and air quality.

Urban trees alter the strength of the Chesapeake Bay breeze by altering the temperature gradient near the coastline. Urban trees on the warm side of the Chesapeake Bay breeze dampen the strength of the breeze and therefore suppress the penetration of the bay breeze inland. The urban trees decrease the near-surface air temperature over the warm land and therefore decrease the temperature gradient between the warm air over land and relatively cool air over the water. For a scenario in which the bay breeze penetrates inland past Baltimore, however, it is found that additional urban trees in Baltimore increase the strength of the bay breeze. The addition of urban trees in Baltimore causes the temperature of the cool side of the bay breeze to decrease, resulting in a stronger temperature gradient and bay breeze. Because the bay breeze can have an impact on air quality, future research can examine how altering the bay breeze through the addition of urban trees can affect air quality.

Because urban areas in the WRF-UCM only include impervious surfaces, buildings, and roads, the WRFUCM with trees can be used to simulate the meteorological conditions under more realistic urban land surface coverage. The National Land Cover dataset used in this study is from 2001. Keeping urban tree fraction and building height datasets up to date is essential for initializing the WRF-UCM with trees, given that the UHI is sensitive to these parameters.

WRF-UCM with trees can be used as a tool to investigate how vegetative land surface changes to urban areas affect many aspects of earth science. Results show that urban trees can lower surface and air temperatures in and downwind of cities and alter a bay breeze. Future studies will investigate how lower summertime buildingsurface temperatures due to an increase in urban trees can result in less energy demand for cooling buildings, will quantify the reduction in energy demand to a decrease in anthropogenic emissions, and will determine 
the impact of urban trees on climate and air quality. The WRF-UCM with trees can be utilized to investigate how changes in urban trees, grass, and/or soil affect the hydrological cycle through changes in runoff, evapotranspiration, and even precipitation both in and downwind of cities.

Acknowledgments. This work was funded by NASA Grant NNX06AF57H ("How do changes to the urban environment affect precipitation and air quality?") and NASA Grant NNX08AR426 ("Tropospheric transport processes for trace gases and aerosols."). We also acknowledge the Maryland Department of the Environment for their support and for allowing use of their observed surface temperature and wind data.

\section{APPENDIX}

\section{Parameterization of Trees in the UCM}

Energy storage and surface temperatures are calculated on the basis of the surface energy balance equation described in both Lee and Park (2008) and Kusaka et al. (2001). The UCM is coupled with the Noah land surface model to obtain the latent and sensible heat fluxes at the soil surface by passing the incident longwave and shortwave radiation at the soil surface. The sensible heat flux of the tree canopy and evapotranspiration flux, which include the moisture flux on tree leaves and transpiration from the root zone, are calculated following Lee and Park (2008). Transpiration from the root zone is a function of stomatal resistance, which is also obtained from the Noah land surface model. Wind speed below treetops is modified to account for the additional trees by using the method of Lee and Park (2008).

The longwave and shortwave radiation fluxes are calculated by blending a vegetated urban canopy model (Lee and Park 2008) and an equation for transmission of radiation through a tree canopy (Annandale et al. 2004; Campbell and Norman 1998; Norman and Welles 1983) with the single-layer urban canopy model (Kusaka et al. 2001; Kusaka and Kimura 2004), which is coupled within the WRF modeling system. For completeness, we review many of the equations used in the vegetated urban canopy model and the single-layer urban canopy model before we present the final blended longwave and shortwave radiation flux equations on the surfaces of buildings, roads, soil/grass, and trees to introduce the variables used in the final merged equations.

For trees taller than the adjacent buildings, the tree canopy is split into two layers: one above the building roof and another in the street canyon. The LAI above the street canyon is calculated by

$$
\mathrm{LAI}_{a}=\left(h_{f}-h_{b}\right) \rho_{l},
$$

and the LAI in the street canyon is defined as

$$
\mathrm{LAI}_{c}=h_{b} \rho_{l} \text {, }
$$

where $h_{f}$ and $h_{b}$ are the tree and building heights, respectively. The density of the leaves is assumed to be invariant with height and is defined by

$$
\rho_{l}=\mathrm{LAI} / h_{f} .
$$

Table A1 lists all of the variables used to parameterize urban trees in the WRF-UCM.

The amount of radiation that can be transmitted through a tree canopy needs to be defined to compute the radiative budget. The transmissivity of radiation through a tree canopy from height $z_{1}$ to $z_{2}$ is computed by

$$
T\left(z_{1}, z_{2}\right)=\exp \left(\int_{z_{1}}^{z_{2}}-0.5 \rho_{l} \sqrt{\alpha} d z\right),
$$

where $\rho_{l}$ is the leaf area density and $\alpha$ represents the absorptivity for individual leaves (Annandale et al. 2004; Campbell and Norman 1998; Norman and Welles 1983). A typical value of $\alpha$ is 0.5 (Annandale et al. 2004) and is used here.

The direct solar radiation that reaches the surface of the leaves in the street canyon is

$$
\begin{aligned}
S_{l}^{D^{*}}= & S_{c}^{D^{\downarrow}} f_{l}\left\{\left[1-T\left(h_{c}, h_{\mathrm{fc}}\right)\right] \sin \theta_{n}\right. \\
& \left.+\left[1-T\left(0, h_{\mathrm{fc}}\right)\right]\left(1-\sin \theta_{n}\right)\right\},
\end{aligned}
$$

where $S_{l}^{D^{*}}, S_{c}^{D^{\downarrow}}, h_{c}$, and $h_{\mathrm{fc}}$ are the downward direct solar radiation that reaches the surface of leaves, downward direct solar radiation in the canyon, the height of the top of the tree in the canyon, and the average tree shaded height due to the buildings, respectively (Lee and Park 2008); here, $\theta_{n}$ is the angle between the average canyon axis and the direction of the sun as described by Kusaka et al. (2001). The first and second terms on the rhs of Eq. (A5) describe the solar radiation that reaches building shaded and unshaded leaves, respectively. If the tree height is greater than the adjacent building height, then $h_{\mathrm{fc}}$ is set to the building height. The height of the shaded canopy is defined by

$$
h_{c}=h_{\mathrm{fc}}-\frac{w}{2 \tan \theta_{z} \sin \theta_{n}},
$$

where $w$ is the width of the ground between the buildings and $\theta_{z}$ is the solar zenith angle. If $h_{c}$ is greater than $h_{\mathrm{fc}}$, 
TABLE A1. Description of symbols used to parameterize trees in UCM.

\begin{tabular}{|c|c|c|}
\hline Symbol & Description & Units \\
\hline LAI & Leaf area index & - \\
\hline LAI* & Effective leaf area index & - \\
\hline$T_{l}$ & Temperature of leaves & $\mathrm{K}$ \\
\hline$T_{\text {la }}$ & Temperature of leaves above roof level & $\mathrm{K}$ \\
\hline$Y$ & Extinction coefficient & - \\
\hline$\varepsilon_{l}$ & Emissivity of leaves & - \\
\hline$\rho_{l}$ & Leaf density & $\mathrm{m}^{-1}$ \\
\hline$\sigma$ & Leaf aspect ratio & - \\
\hline$\alpha$ & Absorptivity of a leaf & - \\
\hline$f_{l}$ & Tree canopy fraction in street canyon & - \\
\hline$f_{\mathrm{rd}}$ & Road fraction of ground in street canyon & - \\
\hline$f_{s}$ & Grass/soil fraction of ground in street canyon & - \\
\hline$h_{f}$ & Tree height & $\mathrm{m}$ \\
\hline$h_{b}$ & Building height & $\mathrm{m}$ \\
\hline$h_{c}$ & Height of top of tree in street canyon & $\mathrm{m}$ \\
\hline$h_{\mathrm{fc}}$ & Average tree-shaded height due to buildings & $\mathrm{m}$ \\
\hline$h_{\mathrm{fa}}$ & Height between the treetop and building roof level & $\mathrm{m}$ \\
\hline$h_{a \rightarrow r_{-} \text {direct }}$ & Distance of path of direct radiation through the tree canopy from the center of the shadow on roof & $\mathrm{m}$ \\
\hline$\theta_{n}$ & Angle between average street axis and sun angle & $\mathrm{rad}$ \\
\hline$\theta_{z}$ & Solar zenith angle & $\mathrm{rad}$ \\
\hline$\alpha_{r}$ & Albedo of roof & - \\
\hline$w$ & Width of the ground between the buildings & $\mathrm{m}$ \\
\hline$l_{\text {shadow }}$ & Normalized shadow length & - \\
\hline$l_{\text {height }}$ & Normalized building height & - \\
\hline$l_{\text {ground }}$ & Normalized street-canyon width & - \\
\hline$l_{\text {shadow_roof }}$ & Normalized shadow on roof & - \\
\hline$T\left(z_{1}, z_{2}\right)$ & Transmissivity between heights $z_{1}$ and $z_{2}$ & - \\
\hline$\tau_{\text {wa }}$ & Wall-atmosphere transmissivity & - \\
\hline$\tau_{\mathrm{ww}}$ & Wall-wall transmissivity & - \\
\hline$\tau_{\mathrm{wg}}$ & Wall-ground transmissivity & - \\
\hline$\tau_{\mathrm{ga}}$ & Ground-atmosphere transmissivity & - \\
\hline$S_{l}^{D *}$ & Downward direct solar radiation reaching leaves & $\mathrm{W} \mathrm{m}^{-2}$ \\
\hline$S_{c}^{D^{\downarrow}}$ & Downward direct solar radiation in street canyon & $\mathrm{W} \mathrm{m}^{-2}$ \\
\hline$S_{w}^{c} D^{\downarrow}$ & Downward direct solar radiation reaching wall & $\mathrm{W} \mathrm{m}^{-2}$ \\
\hline$S_{\text {rd }}^{D \downarrow}$ & Downward direct solar radiation reaching road & $\mathrm{W} \mathrm{m}^{-2}$ \\
\hline$S_{s}^{D^{\downarrow}}$ & Downward direct solar radiation reaching grass/soil & $\mathrm{W} \mathrm{m}^{-2}$ \\
\hline$S_{l}^{I^{\downarrow}}$ & Indirect solar radiation absorbed by leaves & $\mathrm{W} \mathrm{m}^{-2}$ \\
\hline$S_{c}^{I^{\downarrow}}$ & Indirect solar radiation in street canyon & $\mathrm{W} \mathrm{m}^{-2}$ \\
\hline$S_{l}^{I^{*}}$ & Indirect solar radiation reaching leaves if no buildings present & $\mathrm{W} \mathrm{m}^{-2}$ \\
\hline$S_{w}^{I^{\downarrow}}$ & Indirect solar radiation incident on wall & $\mathrm{W} \mathrm{m}^{-2}$ \\
\hline$S_{\mathrm{rd}}^{I^{\downarrow}}$ & Indirect solar radiation incident on road & $\mathrm{W} \mathrm{m} \mathrm{m}^{-2}$ \\
\hline$S_{s}^{I^{\perp}}$ & Indirect solar radiation incident on grass/soil & $\mathrm{W} \mathrm{m}^{-2}$ \\
\hline$S_{w}^{\uparrow \downarrow}$ & Solar radiation absorbed by wall & $\mathrm{W} \mathrm{m}^{-2}$ \\
\hline$S_{\mathrm{rd}}^{\uparrow \downarrow} \downarrow$ & Solar radiation absorbed by road & $\mathrm{W} \mathrm{m}^{-2}$ \\
\hline$S_{s}^{\uparrow \downarrow}$ & Solar radiation absorbed by grass/soil & $\mathrm{W} \mathrm{m}^{-2}$ \\
\hline$S_{l}^{\uparrow \downarrow}$ & Solar radiation absorbed by leaves & $\mathrm{W} \mathrm{m}^{-2}$ \\
\hline$S_{\mathrm{la}}^{D *}$ & Direct solar radiation that reaches leaves above roof level & $\mathrm{W} \mathrm{m}^{-2}$ \\
\hline$S_{a}^{D^{\downarrow}}$ & Direct solar radiation from the atmosphere above & $\mathrm{W} \mathrm{m}^{-2}$ \\
\hline$S_{\text {la }}^{I *}$ & Indirect solar radiation that reaches leaves above roof level & $\mathrm{W} \mathrm{m}^{-2}$ \\
\hline$S_{a}^{I \downarrow}$ & Indirect solar radiation from the atmosphere above & $\mathrm{W} \mathrm{m}{ }^{-2}$ \\
\hline$S_{\mathrm{la}}^{D^{\downarrow}}$ & Direct solar radiation absorbed by leaves above roof level & $\mathrm{W} \mathrm{m}^{-2}$ \\
\hline$S_{\mathrm{la}}^{I \downarrow}$ & Indirect solar radiation absorbed by leaves above roof level & $\mathrm{W} \mathrm{m}^{-2}$ \\
\hline$S_{\text {la_side }}^{D^{\downarrow}}$ & Direct solar radiation absorbed through side of tree canopy above roof level & $\mathrm{W} \mathrm{m}^{-2}$ \\
\hline$S_{\text {la_side }}^{I \downarrow}$ & Indirect solar radiation absorbed through side of tree canopy above roof level & $\mathrm{W} \mathrm{m}^{-2}$ \\
\hline$S_{\text {la } r}^{\downarrow} r$ & Solar radiation reflected by roof and absorbed by tree canopy above roof & $\mathrm{W} \mathrm{m}^{-2}$ \\
\hline$S_{r}^{\uparrow} \bar{l}^{r}$ & Solar radiation absorbed by roof & $\mathrm{W} \mathrm{m}^{-2}$ \\
\hline$L^{c \downarrow}$ & Longwave radiation entering street canyon from aloft & $\mathrm{W} \mathrm{m}^{-2}$ \\
\hline$L_{l \uparrow}^{l}$ & Longwave radiation emitted by leaves that reaches other leaves & $\mathrm{W} \mathrm{m}^{-2}$ \\
\hline
\end{tabular}


TABLE A1. (Continued)

\begin{tabular}{|c|c|c|}
\hline Symbol & Description & Units \\
\hline$L_{l \uparrow}^{a}$ & Longwave radiation emitted by leaves that escapes canyon & $\mathrm{W} \mathrm{m} \mathrm{m}^{-2}$ \\
\hline$L_{l \uparrow}^{w}$ & Longwave radiation emitted by leaves that reaches wall & $\mathrm{W} \mathrm{m} \mathrm{m}^{-2}$ \\
\hline$L_{l \uparrow}^{g}$ & Longwave radiation emitted by leaves that reaches ground & $\mathrm{W} \mathrm{m} \mathrm{m}^{-2}$ \\
\hline$L_{w}^{\uparrow \uparrow}$ & Net longwave radiation on surface of wall & $\mathrm{W} \mathrm{m} \mathrm{m}^{-2}$ \\
\hline$L_{\mathrm{rd}}^{\uparrow \downarrow}$ & Net longwave radiation on surface of road & $\mathrm{W} \mathrm{m} \mathrm{m}^{-2}$ \\
\hline$L_{s}^{\uparrow \downarrow}$ & Net longwave radiation on surface of grass/soil & $\mathrm{W} \mathrm{m} \mathrm{m}^{-2}$ \\
\hline$L_{l}^{\uparrow \downarrow}$ & Net longwave radiation on surface of leaves & $\mathrm{W} \mathrm{m} \mathrm{m}^{-2}$ \\
\hline$L_{l 2}^{l}$ & Longwave radiation emitted by leaves that is absorbed by leaves & $\mathrm{W} \mathrm{m} \mathrm{m}^{-2}$ \\
\hline$L_{\mathrm{rd} 2}^{l}$ & Longwave radiation emitted by the road that is absorbed by leaves & $\mathrm{W} \mathrm{m} \mathrm{m}^{-2}$ \\
\hline$L_{s 2}^{l}$ & Longwave radiation emitted by soil that is absorbed by leaves & $\mathrm{W} \mathrm{m} \mathrm{m}^{-2}$ \\
\hline$L_{w 2}^{l}$ & Longwave radiation emitted by building walls that is absorbed by leaves & $\mathrm{W} \mathrm{m} \mathrm{m}^{-2}$ \\
\hline$L_{c 2}^{l}$ & Downwelling longwave radiation from above the urban canopy that is absorbed by leaves & $\mathrm{W} \mathrm{m} \mathrm{m}^{-2}$ \\
\hline$L_{\mathrm{la} \uparrow}^{c}$ & Longwave radiation emitted from the tree canopy above the rooftop that enters the street canyon & $\mathrm{W} \mathrm{m} \mathrm{m}^{-2}$ \\
\hline$L_{\mathrm{la} \uparrow}$ & Longwave radiation emitted from leaves above roof level & $\mathrm{W} \mathrm{m} \mathrm{m}^{-2}$ \\
\hline$L_{\text {la } \uparrow}^{\text {la }}$ & Longwave radiation emitted from leaves that reaches the surface of other leaves above the roof height & $\mathrm{W} \mathrm{m} \mathrm{m}^{-2}$ \\
\hline$L_{r}^{\uparrow \downarrow}$ & Longwave radiation absorbed by roof & $\mathrm{W} \mathrm{m} \mathrm{m}^{-2}$ \\
\hline$L_{\mathrm{la}}^{\uparrow \downarrow}$ & Longwave radiation absorbed by leaves above roof level & $\mathrm{W} \mathrm{m}{ }^{-2}$ \\
\hline$F_{w \leftrightarrow a}$ & Wall-atmosphere view factor & - \\
\hline$F_{g \leftrightarrow a}$ & Ground-atmosphere view factor & - \\
\hline$F_{w \leftrightarrow g}$ & Wall-ground view factor & - \\
\hline$F_{w \leftrightarrow w}$ & Wall-wall view factor & - \\
\hline$F_{l \leftrightarrow a}$ & Leaves-atmosphere view factor & - \\
\hline$F_{l \leftrightarrow g}$ & Leaves-ground view factor & - \\
\hline$F_{l \leftrightarrow w}$ & Leaves-wall view factor & - \\
\hline$F_{\text {la_side } \leftrightarrow \mathrm{a}}$ & Side of tree canopy above roof-sky view factor & - \\
\hline$F_{\text {la_side } \leftrightarrow \mathrm{r}}$ & Side of tree canopy above roof-roof view factor & - \\
\hline$C_{l}$ & Specific heat capacity of leaves & $\mathrm{J} \mathrm{m}^{-2} \mathrm{~K}^{-1}$ \\
\hline$H_{l}$ & Sensible heat flux of leaves & $\mathrm{W} \mathrm{m}^{-2}$ \\
\hline$E_{l}$ & Moisture flux on leaves & $\mathrm{kg} \mathrm{m}^{-2} \mathrm{~s}^{-1}$ \\
\hline$E_{\text {root }}$ & Transpiration from root zone & $\mathrm{kg} \mathrm{m}^{-2} \mathrm{~s}^{-1}$ \\
\hline$L_{v}$ & Latent heat of vaporization & $\mathrm{J} \mathrm{kg}^{-1}$ \\
\hline$C_{w 1 \mathrm{~mm}}$ & Specific heat capacity of $1-\mathrm{mm}$ water depth & $\mathrm{J} \mathrm{m}^{-2} \mathrm{~K}^{-1}$ \\
\hline
\end{tabular}

then $h_{c}$ is set to $h_{\mathrm{fc}}$. The direct solar radiation absorbed by the leaves is

$$
S_{l}^{D^{\downarrow}}=\frac{s_{l}^{D^{\downarrow}}\left(1-\alpha_{l}\right)}{\sigma_{l}},
$$

and the direct solar radiation reaching the surface of the wall, ground, and grass/soil is

$$
\begin{aligned}
& S_{w}^{D \downarrow}=\left(S_{c}^{D^{\downarrow}}-S_{l}^{D^{*}}\right) \frac{l_{\text {shadow }}}{2 l_{\text {height }}} \\
& S_{\mathrm{rd}}^{D^{\downarrow}}=f_{\mathrm{rd}}\left(S_{c}^{D^{\downarrow}}-S_{l}^{D^{*}}\right) \frac{l_{\text {ground }}-l_{\text {shadow }}}{l_{\text {ground }}}, \text { and } \\
& S_{s}^{D^{\downarrow}}=f_{s}\left(S_{c}^{D^{\downarrow}}-S_{l}^{D^{*}}\right) \frac{l_{\text {ground }}-l_{\text {shadow }}}{l_{\text {ground }}},
\end{aligned}
$$

where $f_{\text {rd }}$ and $f_{s}$ define the fraction of the ground that is road and grass/soil, respectively, and $l_{\text {shadow }}, l_{\text {height }}$, and $l_{\text {ground }}$ are the normalized shadow length, normalized building height, and normalized street-canyon width, respectively, as defined by Kusaka et al. (2001). The solar radiation absorbed by the leaves is a function of the leaf aspect ratio $\sigma_{l}$, which is defined as

$$
\sigma_{l}=\mathrm{LAI} * f_{l},
$$

where the effective leaf area index is

$$
\mathrm{LAI}^{*}=2.5[1-\exp (-0.4 \mathrm{LAI})],
$$

as described by Lee and Park (2008).

The indirect solar radiation reaching the surface of the leaves if buildings cause no shade is defined by

$$
S_{l}^{I^{*}}=S_{c}^{I^{\downarrow}} f_{l}\left[1-T\left(0, h_{f}\right)\right],
$$

where $S_{c}^{I \downarrow}$ is the downward indirect solar radiation at the top of the street canyon (i.e., roof level) (Lee and Park 2008). 
The indirect solar radiation flux absorbed by the leaves is (Lee and Park 2008)

$$
S_{l}^{I^{\downarrow}}=\frac{S_{l}^{I^{*}} F_{l \leftrightarrow a}\left(1-\alpha_{l}\right)}{\sigma_{l}},
$$

and the indirect solar radiation incident on the surfaces of the wall, road, and soil is (Lee and Park 2008)

$$
\begin{aligned}
& S_{w}^{I^{\downarrow}}=F_{w \leftrightarrow a}\left(S_{c}^{I^{\downarrow}}-S_{l}^{I^{*}}\right), \\
& S_{\mathrm{rd}}^{I^{\downarrow}}=f_{\mathrm{rd}} F_{g \leftrightarrow a}\left(S_{c}^{I^{\downarrow}}-S_{l}^{I^{*}}\right), \quad \text { and } \\
& S_{s}^{I^{\downarrow}}=f_{s} F_{g \leftrightarrow a}\left(S_{c}^{I^{\downarrow}}-S_{l}^{I^{*}}\right),
\end{aligned}
$$

where $F_{w \leftrightarrow a}$ and $F_{g \leftrightarrow a}$ are the sky view factors at the center of the wall and ground and $F_{l \leftrightarrow a}$ is the sky view factor of the leaves at one-half of the height of the tree. The sky view factors are computed with the same algorithm as shown in Kusaka et al. (2001).

The mean radiative transmissivities due to the tree canopy within the street canyon are calculated by (Lee and Park 2008)

$$
\begin{gathered}
\tau_{\mathrm{wa}}=1-f_{l}\left[1-T\left(\frac{3}{4} h_{b}, h_{\mathrm{fc}}\right)\right], \\
\tau_{\mathrm{ww}}=1-f_{l}\left[1-T\left(\frac{1}{4} h_{b}, \frac{3}{4} h_{b}\right)\right],
\end{gathered}
$$

$$
\begin{aligned}
\tau_{\mathrm{wg}} & =1-f_{l}\left[1-T\left(0, \frac{1}{4} h_{b}\right)\right], \quad \text { and } \\
\tau_{\mathrm{ga}} & =1-f_{l}\left[1-T\left(0, h_{\mathrm{fc}}\right)\right]
\end{aligned}
$$

where $\tau_{\mathrm{wa}}, \tau_{\mathrm{ww}}, \tau_{\mathrm{wg}}$, and $\tau_{\mathrm{ga}}$ represent the respective transmissivities between the wall and atmosphere above the canyon, between two building walls, between wall and ground, and between ground and atmosphere above the canyon. The UCM allows for solar radiation to be reflected twice within the urban canopy. The solar radiation absorbed by the building wall, road, soil/grass, and tree leaves is defined, respectively, as

$$
\begin{aligned}
S_{w}^{\uparrow \downarrow}= & \left(1-\alpha_{w}\right)\left[S_{w}^{I^{\downarrow}}+S_{w}^{D^{\downarrow}}+\tau_{\mathrm{wg}} \alpha_{\mathrm{rd}}\left(S_{\mathrm{rd}}^{I^{\downarrow}}+S_{\mathrm{rd}}^{D^{\downarrow}}\right) F_{g \leftrightarrow w}\right. \\
& +\tau_{\mathrm{wg}} \alpha_{s}\left(S_{s}^{I^{\downarrow}}+S_{s}^{D^{\downarrow}}\right) F_{g \leftrightarrow w} \\
& \left.+\tau_{\mathrm{ww}} \alpha_{w}\left(S_{w}^{I^{\downarrow}}+S_{w}^{D^{\downarrow}}\right) F_{w \leftrightarrow w}\right], \\
S_{\mathrm{rd}}^{\uparrow \downarrow}= & \left(1-\alpha_{\mathrm{rd}}\right)\left[S_{\mathrm{rd}}^{I^{\downarrow}}+S_{\mathrm{rd}}^{D^{\downarrow}}+\tau_{\mathrm{wg}} f_{\mathrm{rd}} \alpha_{w}\left(S_{w}^{I^{\downarrow}}+S_{w}^{D^{\downarrow}}\right) F_{g \leftrightarrow w}\right],
\end{aligned}
$$

$$
S_{s}^{\uparrow \downarrow}=\left(1-\alpha_{s}\right)\left[S_{s}^{I^{\downarrow}}+S_{s}^{D^{\downarrow}}+\tau_{\mathrm{wg}} f_{s} \alpha_{w}\left(S_{w}^{I^{\downarrow}}+S_{w}^{D^{\downarrow}}\right) F_{g \leftrightarrow w}\right],
$$

and

$$
\begin{aligned}
S_{l}^{\uparrow \downarrow}= & S_{l}^{I^{\downarrow}}+S_{l}^{D^{\downarrow}}\left(1-\alpha_{l}\right)\left[\left(1-\tau_{\mathrm{wg}}\right) \alpha_{\mathrm{rd}}\left(S_{\mathrm{rd}}^{I^{\downarrow}}+S_{\mathrm{rd}}^{D^{\downarrow}}\right) F_{w \leftrightarrow g}+\left(1-\tau_{\mathrm{wg}}\right) \alpha_{s}\left(S_{s}^{I^{\downarrow}}+S_{s}^{D^{\downarrow}}\right) F_{w \leftrightarrow g}\right. \\
& +\left(1-\tau_{\mathrm{ww}}\right) \alpha_{w}\left(S_{w}^{I^{\downarrow}}+S_{w}^{D^{\downarrow}}\right) F_{w \leftrightarrow w}+\left(1-\tau_{\mathrm{wg}}\right) f_{\mathrm{rd}} \alpha_{w}\left(S_{w}^{I^{\downarrow}}+S_{w}^{D^{\downarrow}}\right) F_{g \leftrightarrow w}+\left(1-\tau_{\mathrm{wg}}\right) f_{s} \alpha_{w}\left(S_{w}^{I^{\downarrow}}+S_{w}^{D^{\downarrow}}\right) F_{g \leftrightarrow w} \\
& \left.+\left(1-\tau_{\mathrm{wa}}\right) \alpha_{w}\left(S_{w}^{I^{\downarrow}}+S_{w}^{D^{\downarrow}}\right) F_{a \leftrightarrow w}+\left(1-\tau_{\mathrm{ga}}\right) \alpha_{\mathrm{rd}}\left(S_{\mathrm{rd}}^{I^{\downarrow}}+S_{\mathrm{rd}}^{D^{\downarrow}}\right) F_{a \leftrightarrow g}+\left(1-\tau_{\mathrm{ga}}\right) \alpha_{s}\left(S_{s}^{I^{\downarrow}}+S_{s}^{D^{\downarrow}}\right) F_{a \leftrightarrow g}\right],
\end{aligned}
$$

where subscripts $w, g$, and $a$ represent the wall, ground, and atmosphere above the canopy, respectively, and $F$ is the view factor, which is calculated in the UCM as given in Kusaka et al. (2001).

Longwave radiation is emitted isotropically from the tree canopy. Some of the radiation emitted from the tree leaves reaches the surface of other leaves within the tree canopy while the remainder reaches the ground, building walls, or atmosphere above the street canyon. The longwave radiation emitted from tree leaves that reaches the surfaces of other leaves, the atmosphere above the canyon, building walls, and the ground is defined as in Lee and Park (2008):

$$
\begin{aligned}
& L_{l \uparrow}^{l}=L_{l \uparrow} f_{l}\left[1-T\left(0, h_{\mathrm{fc}}\right)\right], \\
& L_{l \uparrow}^{a}=0.5 \sigma_{l}\left(L_{l \uparrow}-L_{l \uparrow}^{l}\right) F_{l \leftrightarrow a}, \\
& L_{l \uparrow}^{w}=\frac{w}{2 h_{b}} 0.5 \sigma_{l}\left(L_{l \uparrow}-L_{l \uparrow}^{l}\right)\left(2-F_{l \leftrightarrow a}-F_{l \leftrightarrow g}\right),
\end{aligned}
$$




$$
L_{l \uparrow}^{g}=0.5 \sigma_{l}\left(L_{l \uparrow}-L_{l \uparrow}^{l}\right) F_{l \leftrightarrow g},
$$

where $w$ is the width of the ground and $L_{l \uparrow}$ is defined as

$$
L_{l \uparrow}=\varepsilon_{l} \sigma_{l} T_{l}^{4},
$$

with $\varepsilon_{l}$ and $T_{l}$ being the emissivity and temperature of the leaves, respectively. The UCM allows for longwave radiation to be reflected twice within the urban canopy.
The net longwave radiation at the surfaces of the building walls, roads, grass/soil, and trees is obtained by incorporating the downwelling atmospheric longwave radiation; longwave radiation emitted by building walls and roofs, roads, grass/soil, and trees; and multiple reflections in the urban street canyon. The net longwave radiation at the surface of the wall is

$$
\begin{aligned}
L_{w}^{\uparrow \downarrow}= & \varepsilon_{w}\left\{\tau_{\mathrm{wa}} L^{c \downarrow} F_{w \leftrightarrow a}+\tau_{\mathrm{wg}}\left(f_{\mathrm{rd}} \varepsilon_{\mathrm{rd}} F_{w \leftrightarrow g} \sigma T_{\mathrm{rd}}^{4}+f_{s} \varepsilon_{s} F_{w \leftrightarrow g} \sigma T_{s}^{4}\right)+\tau_{\mathrm{ww}} \varepsilon_{w} F_{w \leftrightarrow w} \sigma T_{w}^{4}+L_{l \uparrow}^{w}-\sigma T_{w}^{4}\right. \\
& +\tau_{\mathrm{wg}}\left[f_{\mathrm{rd}}\left(1-\varepsilon_{\mathrm{rd}}\right) F_{w \leftrightarrow g} L_{l \uparrow}^{\mathrm{rd}}+f_{s}\left(1-\varepsilon_{s}\right) F_{w \leftrightarrow g} L_{l \uparrow}^{g}\right]+\tau_{\mathrm{ww}}\left(1-\varepsilon_{w}\right) F_{w \leftrightarrow w} L_{l \uparrow}^{w}+\tau_{\mathrm{wg}} \tau_{\mathrm{wa}}\left[f_{\mathrm{rd}}\left(1-\varepsilon_{\mathrm{rd}}\right) F_{w \leftrightarrow g} F_{g \leftrightarrow a} L^{c \downarrow}\right. \\
& \left.+f_{s}\left(1-\varepsilon_{s}\right) F_{w \leftrightarrow g} F_{g \leftrightarrow a} L^{c \downarrow}\right]+\tau_{\mathrm{wg}} \tau_{\mathrm{wg}}\left[f_{\mathrm{rd}}\left(1-\varepsilon_{\mathrm{rd}}\right) F_{w \leftrightarrow g} F_{w \leftrightarrow g} \varepsilon_{w} \sigma T_{w}^{4}+f_{s}\left(1-\varepsilon_{s}\right) F_{w \leftrightarrow g} F_{w \leftrightarrow g} \varepsilon_{w} \sigma T_{w}^{4}\right] \\
& +\tau_{\mathrm{ww}} \tau_{\mathrm{wg}}\left[f_{\mathrm{rd}}\left(1-\varepsilon_{w}\right) F_{w \leftrightarrow w} F_{w \leftrightarrow g} \varepsilon_{g} \sigma T_{g}^{4}+f_{s}\left(1-\varepsilon_{w}\right) F_{w \leftrightarrow w} F_{w \leftrightarrow g} \varepsilon_{s} \sigma T_{s}^{4}\right]+\tau_{\mathrm{ww}} \tau_{\mathrm{wa}}\left(1-\varepsilon_{w}\right) F_{w \leftrightarrow w} F_{w \leftrightarrow a} L^{c \downarrow} \\
& \left.+\tau_{\mathrm{ww}} \tau_{\mathrm{ww}}\left(1-\varepsilon_{w}\right) F_{w \leftrightarrow w} F_{w \leftrightarrow w} \varepsilon_{w} \sigma T_{w}^{4}\right\} .
\end{aligned}
$$

Here, $L^{c \downarrow}$ is the net longwave radiation entering the street canyon from aloft. The net longwave radiation at the surface of the road is

$$
\begin{aligned}
L_{\mathrm{rd}}^{\uparrow \downarrow}= & f_{\mathrm{rd}} \varepsilon_{\mathrm{rd}}\left\{\tau_{\mathrm{ga}} L^{c \downarrow} F_{g \leftrightarrow a}+\tau_{\mathrm{wg}} \varepsilon_{w} F_{w \leftrightarrow g} \sigma T_{w}^{4}+L_{l \uparrow}^{g}-\sigma T_{\mathrm{rd}}^{4}+\tau_{\mathrm{wg}}\left(1-\varepsilon_{w}\right) F_{g \leftrightarrow w} L_{l \uparrow}^{w}+\tau_{\mathrm{wg}} \tau_{\mathrm{wa}}\left(1-\varepsilon_{w}\right) F_{g \leftrightarrow w} F_{w \leftrightarrow a} L^{c \downarrow}\right. \\
& \left.+\tau_{\mathrm{wg}} \tau_{\mathrm{ww}} F_{g \leftrightarrow w} F_{w \leftrightarrow w} \varepsilon_{w} \sigma T_{w}^{4}+\tau_{\mathrm{wg}} \tau_{\mathrm{wg}}\left[f_{\mathrm{rd}}\left(1-\varepsilon_{w}\right) F_{g \leftrightarrow w} F_{w \leftrightarrow g} \varepsilon_{\mathrm{rd}} \sigma T_{\mathrm{rd}}^{4}+f_{s}\left(1-\varepsilon_{w}\right) F_{g \leftrightarrow w} F_{w \leftrightarrow g} \varepsilon_{s} \sigma T_{s}^{4}\right]\right\} .
\end{aligned}
$$

The net longwave radiation at the surface of the grass/soil is

$$
\begin{aligned}
L_{s}^{\uparrow \downarrow}= & f_{s} \varepsilon_{s}\left\{\tau_{\mathrm{ga}} L^{c \downarrow} F_{g \leftrightarrow a}+\tau_{\mathrm{wg}} \varepsilon_{w} F_{w \leftrightarrow g} \sigma T_{w}^{4}+L_{l \uparrow}^{g}-\sigma T_{s}^{4}+\tau_{\mathrm{wg}}\left(1-\varepsilon_{w}\right) F_{g \leftrightarrow w} L_{l \uparrow}^{w}+\tau_{\mathrm{wg}} \tau_{\mathrm{wa}}\left(1-\varepsilon_{w}\right) F_{g \leftrightarrow w} F_{w \leftrightarrow a} L^{c \downarrow}\right. \\
& \left.+\tau_{\mathrm{wg}} \tau_{\mathrm{ww}} F_{g \leftrightarrow w} F_{w \leftrightarrow w} \varepsilon_{w} \sigma T_{w}^{4}+\tau_{\mathrm{wg}} \tau_{\mathrm{wg}}\left[f_{\mathrm{rd}}\left(1-\varepsilon_{w}\right) F_{g \leftrightarrow w} F_{w \leftrightarrow g} \varepsilon_{\mathrm{rd}} \sigma T_{\mathrm{rd}}^{4}+f_{s}\left(1-\varepsilon_{w}\right) F_{g \leftrightarrow w} F_{w \leftrightarrow g} \varepsilon_{s} \sigma T_{s}^{4}\right]\right\} .
\end{aligned}
$$

The net longwave radiation on the surface of leaves is

$$
L_{l}^{\uparrow \downarrow}=L_{c 2}^{l}+L_{l 2}^{l}+L_{\mathrm{rd} 2}^{l}+L_{s 2}^{l}+L_{w 2}^{l}-L_{l \uparrow},
$$

where $L_{c 2}^{l}$ represents the downwelling longwave radiation from the atmosphere above the street canyon that is absorbed by the tree canopy and $L_{l 2}^{l}, L_{\mathrm{rd} 2}^{l}, L_{s 2}^{l}$, and $L_{w 2}^{l}$ represent the longwave radiation emitted from the tree canopy, roads, soil, and building walls, respectively, that is absorbed by the tree canopy. Quantities $L_{c 2}^{l}, L_{l 2}^{l}, L_{\mathrm{rd} 2}^{l}, L_{s 2}^{l}$, and $L_{w 2}^{l}$ take into account multiple reflections from the building walls, road, and soil in the urban street canyon and are calculated as

$$
\begin{aligned}
L_{c 2}^{l}= & \frac{\varepsilon_{l}}{\sigma_{l}}\left\{f_{\mathrm{rd}} L^{c \downarrow} F_{g \leftrightarrow a}\left(1-\tau_{\mathrm{ga}}\right)+f_{s} L^{c \downarrow} F_{g \leftrightarrow a}\left(1-\tau_{\mathrm{ga}}\right)+\left(1-\tau_{\mathrm{ga}}\right)\left[\tau_{\mathrm{ga}} f_{\mathrm{rd}}\left(1-\varepsilon_{\mathrm{rd}}\right) F_{g \leftrightarrow a} F_{a \leftrightarrow g} L^{c \downarrow}\right.\right. \\
& \left.+\tau_{\mathrm{ga}} f_{s}\left(1-\varepsilon_{s}\right) F_{g \leftrightarrow a} F_{a \leftrightarrow g} L^{c \downarrow}\right]+\left(1-\tau_{\mathrm{wa}}\right) \tau_{\mathrm{wa}}\left(1-\varepsilon_{w}\right) F_{w \leftrightarrow a} F_{a \leftrightarrow w} L^{c \downarrow}+\tau_{\mathrm{ga}}\left(1-\tau_{\mathrm{ww}}\right)\left[f_{\mathrm{rd}}\left(1-\varepsilon_{\mathrm{rd}}\right) F_{w \leftrightarrow g} F_{g \leftrightarrow a} L^{c \downarrow}\right. \\
& \left.+f_{s}\left(1-\varepsilon_{s}\right) F_{w \leftrightarrow g} F_{g \leftrightarrow a} L^{c \downarrow}\right]+\tau_{\mathrm{wa}}\left(1-\tau_{\mathrm{ww}}\right)\left(1-\varepsilon_{w}\right) F_{w \leftrightarrow w} F_{w \leftrightarrow a} L^{c \downarrow}+\tau_{\mathrm{wa}}\left(1-\tau_{\mathrm{wg}}\right)\left[f_{\mathrm{rd}}\left(1-\varepsilon_{w}\right) F_{g \leftrightarrow w} F_{w \leftrightarrow a} L^{c \downarrow}\right. \\
& \left.\left.+f_{s}\left(1-\varepsilon_{w}\right) F_{g \leftrightarrow w} F_{w \leftrightarrow a} L^{c \downarrow}\right]\right\},
\end{aligned}
$$




$$
\begin{aligned}
& L_{l 2}^{l}=L_{l \uparrow}^{l} \frac{\varepsilon_{l}}{\sigma_{l}}\left\{\left(1-\tau_{\mathrm{ga}}\right)\left[f_{\mathrm{rd}}\left(1-\varepsilon_{\mathrm{rd}}\right) F_{g \leftrightarrow a} L_{l \uparrow}^{g}+f_{s}\left(1-\varepsilon_{s}\right) F_{g \leftrightarrow a} L_{l \uparrow}^{g}\right]+\left(1-\tau_{\mathrm{wa}}\right)\left(1-\varepsilon_{w}\right) F_{w \leftrightarrow a} L_{l \uparrow}^{w}\right. \\
& +\left(1-\tau_{\mathrm{wg}}\right)\left[f_{\mathrm{rd}}\left(1-\varepsilon_{\mathrm{rd}}\right) F_{w \leftrightarrow g} L_{l \uparrow}^{g}+f_{s}\left(1-\varepsilon_{s}\right) F_{w \leftrightarrow g} L_{l \uparrow}^{g}\right]+\left(1-\tau_{\mathrm{ww}}\right)\left(1-\varepsilon_{w}\right) F_{w \leftrightarrow w} L_{l \uparrow}^{w} \\
& \left.+\left(1-\tau_{\mathrm{wg}}\right)\left[f_{\mathrm{rd}}\left(1-\varepsilon_{w}\right) F_{g \leftrightarrow w} L_{l \uparrow}^{w}+f_{s}\left(1-\varepsilon_{w}\right) F_{g \leftrightarrow w} L_{l \uparrow}^{w}\right]\right\}, \\
& L_{\mathrm{rd} 2}^{l}=\frac{\varepsilon_{l}}{\sigma_{l}}\left[f_{\mathrm{rd}} F_{g \leftrightarrow w} \varepsilon_{\mathrm{rd}} \sigma T_{\mathrm{rd}}^{4}\left(1-\tau_{\mathrm{wg}}\right)+f_{\mathrm{rd}} F_{g \leftrightarrow a} \varepsilon_{\mathrm{rd}} \sigma T_{\mathrm{rd}}^{4}\left(1-\tau_{\mathrm{ga}}\right)+\left(1-\tau_{\mathrm{wa}}\right) \tau_{\mathrm{wg}}\left(1-\varepsilon_{w}\right) F_{w \leftrightarrow a} F_{g \leftrightarrow w} \varepsilon_{\mathrm{rd}} \sigma T_{\mathrm{rd}}^{4}\right. \\
& +\tau_{\mathrm{wg}}\left(1-\tau_{\mathrm{ww}}\right) f_{\mathrm{rd}}\left(1-\varepsilon_{w}\right) F_{w \leftrightarrow w} F_{w \leftrightarrow g} \varepsilon_{\mathrm{rd}} \sigma T_{\mathrm{rd}}^{4}+\tau_{\mathrm{wg}}\left(1-\tau_{\mathrm{wg}}\right) f_{\mathrm{rd}} f_{\mathrm{rd}}\left(1-\varepsilon_{w}\right) F_{w \leftrightarrow g} F_{g \leftrightarrow w} \varepsilon_{\mathrm{rd}} \sigma T_{\mathrm{rd}}^{4} \\
& \left.+\tau_{\mathrm{wg}}\left(1-\tau_{\mathrm{wg}}\right) f_{s} f_{\mathrm{rd}}\left(1-\varepsilon_{w}\right) F_{g \leftrightarrow w} F_{w \leftrightarrow g} \varepsilon_{\mathrm{rd}} \sigma T_{\mathrm{rd}}^{4}\right], \\
& L_{s 2}^{l}=\frac{\varepsilon_{l}}{\sigma_{l}}\left[f_{s} F_{g \leftrightarrow w} \varepsilon_{s} \sigma T_{s}^{4}\left(1-\tau_{\mathrm{wg}}\right)+f_{s} F_{g \leftrightarrow a} \varepsilon_{s} \sigma T_{s}^{4}\left(1-\tau_{\mathrm{ga}}\right)+\left(1-\tau_{\mathrm{wa}}\right) \tau_{\mathrm{wg}}\left(1-\varepsilon_{w}\right) F_{w \leftrightarrow a} F_{g \leftrightarrow w} \varepsilon_{s} \sigma T_{s}^{4}\right. \\
& +\tau_{\mathrm{wg}}\left(1-\tau_{\mathrm{ww}}\right) f_{s}\left(1-\varepsilon_{w}\right) F_{w \leftrightarrow w} F_{w \leftrightarrow g} \varepsilon_{s} \sigma T_{s}^{4}+\tau_{\mathrm{wg}}\left(1-\tau_{\mathrm{wg}}\right) f_{s} f_{s}\left(1-\varepsilon_{w}\right) F_{w \leftrightarrow g} F_{g \leftrightarrow w} \varepsilon_{s} \sigma T_{s}^{4} \\
& \left.+\tau_{\mathrm{wg}}\left(1-\tau_{\mathrm{wg}}\right) f_{s} f_{s}\left(1-\varepsilon_{w}\right) F_{g \leftrightarrow w} F_{w \leftrightarrow g} \varepsilon_{s} \sigma T_{s}^{4}\right], \quad \text { and } \\
& L_{w 2}^{l}=\frac{\varepsilon_{l}}{\sigma_{l}}\left\{f_{\mathrm{rd}} F_{g \leftrightarrow w} \varepsilon_{w} \sigma T_{w}^{4}\left(1-\tau_{\mathrm{wg}}\right)+f_{s} F_{g \leftrightarrow w} \varepsilon_{w} \sigma T_{w}^{4}\left(1-\tau_{\mathrm{wg}}\right)+F_{w \leftrightarrow w} \varepsilon_{w} \sigma T_{w}^{4}\left(1-\tau_{\mathrm{ww}}\right)+F_{w \leftrightarrow a} \varepsilon_{w} \sigma T_{w}^{4}\left(1-\tau_{\mathrm{wa}}\right)\right. \\
& +\left(1-\tau_{\mathrm{ga}}\right)\left[\tau_{\mathrm{wg}} f_{\mathrm{rd}}\left(1-\varepsilon_{\mathrm{rd}}\right) F_{g \leftrightarrow a} F_{w \leftrightarrow g} \varepsilon_{w} \sigma T_{w}^{4}+\tau_{\mathrm{wg}} f_{s}\left(1-\varepsilon_{s}\right) F_{g \leftrightarrow a} F_{w \leftrightarrow g} \varepsilon_{w} \sigma T_{w}^{4}\right] \\
& +\left(1-\tau_{\mathrm{wa}}\right) \tau_{\mathrm{ww}}\left(1-\varepsilon_{w}\right) F_{w \leftrightarrow a} F_{w \leftrightarrow w} \varepsilon_{w} \sigma T_{w}^{4}+\tau_{\mathrm{wg}}\left(1-\tau_{\mathrm{wg}}\right)\left[f_{\mathrm{rd}}\left(1-\varepsilon_{\mathrm{rd}}\right) F_{g \leftrightarrow w} F_{w \leftrightarrow g} \varepsilon_{w} \sigma T_{w}^{4}\right. \\
& \left.+f_{s}\left(1-\varepsilon_{s}\right) F_{g \leftrightarrow w} F_{w \leftrightarrow g} \varepsilon_{w} \sigma T_{w}^{4}\right]+\tau_{\mathrm{ww}}\left(1-\tau_{\mathrm{ww}}\right)\left(1-\varepsilon_{w}\right) F_{w \leftrightarrow w} F_{w \leftrightarrow w} \varepsilon_{w} \sigma T_{w}^{4} \\
& \left.+\tau_{\mathrm{ww}}\left(1-\tau_{\mathrm{wg}}\right)\left[f_{\mathrm{rd}}\left(1-\varepsilon_{w}\right) F_{w \leftrightarrow g} F_{w \leftrightarrow w} \varepsilon_{w} \sigma T_{w}^{4}+f_{s}\left(1-\varepsilon_{w}\right) F_{w \leftrightarrow g} F_{w \leftrightarrow w} \varepsilon_{w} \sigma T_{w}^{4}\right]\right\} .
\end{aligned}
$$

If trees are taller than the adjacent buildings, then the heat and moisture fluxes are calculated for the portion of the tree canopy above the roof height and tree shading of the roof is considered. The direct solar radiation and indirect solar radiation that reaches the leaves above the roof height are

$$
\begin{aligned}
S_{\mathrm{la}}^{D^{*}} & =S_{a}^{D^{\downarrow}} f_{l}\left[1-T\left(0, h_{\mathrm{fa}}\right)\right] \quad \text { and } \\
S_{\mathrm{la}}^{I^{*}} & =S_{a}^{I^{\downarrow}} f_{l}\left[1-T\left(0, h_{\mathrm{fa}}\right)\right]
\end{aligned}
$$

where $S_{\mathrm{la}}^{D^{*}}, S_{a}^{D^{\downarrow}}, S_{\mathrm{la}}^{I^{*}}, S_{a}^{I^{\downarrow}}$, and $h_{\mathrm{fa}}$ are the downward direct solar radiation that reaches the surfaces of the leaves, downward direct solar radiation from the atmosphere above, downward indirect solar radiation reaching the surfaces of the leaves, downward indirect solar radiation from the atmosphere, and height between the treetop and building roof level, respectively. The amounts of direct and indirect solar radiation absorbed by the tree canopy entering the top of the tree canopy are defined as

$$
\begin{gathered}
S_{\mathrm{la}}^{D^{\downarrow}}=\frac{S_{\mathrm{la}}^{D^{*}}\left(1-\alpha_{l}\right)}{\sigma_{l}} \text { and } \\
S_{\mathrm{la}}^{I^{\downarrow}}=\frac{S_{\mathrm{la}}^{l^{*}}\left(1-\alpha_{l}\right)}{\sigma_{l}} .
\end{gathered}
$$

Solar radiation is also transmitted through the sides of the tree canopy above the roof. The respective direct solar radiation and indirect solar radiation absorbed through the side of the tree canopy are

$$
S_{\text {la_side }}^{D^{\downarrow}}=\frac{l_{\text {shadow_roof }}}{h_{\mathrm{fa}}} \frac{S_{\text {la }}^{D^{*}}\left(1-\alpha_{l}\right)}{\sigma_{l}} \quad \text { and }
$$




$$
S_{\text {la_side }}^{l^{\downarrow}}=\frac{S_{\mathrm{la}}^{I^{*}}\left(1-\alpha_{l}\right) F_{\text {la_side } \leftrightarrow \mathrm{a}}}{\sigma_{l}},
$$

where $l_{\text {shadow_roof }}$ and $F_{\text {la_side } \leftrightarrow \mathrm{a}}$ are the normalized shadow on the roof and the view factor between the side of the tree canopy and the atmosphere above, respectively. The amount of solar radiation reflected from the roof and absorbed by the tree canopy is

$$
S_{\text {la_r }}^{\downarrow}=\frac{S_{r}^{\uparrow \downarrow}\left[1-T\left(0, h_{\mathrm{fa}}\right)\right] f_{l} \alpha_{r}\left(1-\alpha_{l}\right) F_{\text {la_side } \leftrightarrow \mathrm{r}}}{\left(1-\alpha_{r}\right) \sigma_{l}},
$$

where $S_{r}^{\uparrow}, \alpha_{r}$, and $F_{\text {la_side } \leftrightarrow \text { r }}$ are the solar radiation absorbed by the roof, albedo of the roof, and view factor between the roof and the side of the tree canopy, respectively. So, the solar radiative flux on the tree canopy above the rooftop is

$$
S_{\mathrm{la}}=S_{\mathrm{la}}^{D^{\downarrow}}+S_{\mathrm{la}}^{I^{\downarrow}}+S_{\text {la_side }}^{D^{\downarrow}}+S_{\text {la_side }}^{I^{\downarrow}}+S_{\text {la_r }}^{\downarrow} .
$$

The solar radiative flux on the roof is

$$
\begin{aligned}
S_{r}^{\uparrow \downarrow}= & \frac{l_{\text {roof }}-l_{\text {shadow }_{\text {roof }}}}{l_{\text {roof }}}\left(1-\alpha_{r}\right) S_{a}^{D^{\downarrow}}+\left(1-\frac{l_{\text {roof }}-l_{\text {shadow }_{\text {roof }}}}{l_{\text {roof }}}\right)\left(1-\alpha_{r}\right) S_{a}^{D^{\downarrow}}\left\{1-f_{l}\left[1-T\left(0, h_{a \rightarrow r_{\text {direct }}}\right)\right]\right\} \\
& +S_{a}^{I^{\downarrow}}\left(1-\alpha_{r}\right) F_{r \rightarrow a}+S_{a}^{I^{\downarrow}}\left(1-\alpha_{r}\right)\left(1-F_{r \rightarrow a}\right)\left\{1-f_{l}\left[1-T\left(0, h_{\mathrm{fa}}\right)\right]\right\},
\end{aligned}
$$

where $h_{a \rightarrow r_{\text {direct }}}$ is the distance of the path of the direct radiation through the tree canopy from the center of the shadow on the roof $\left(l_{\text {shadow }_{\text {roof }}} / 2\right)$. The first term in Eq. (A48) is the amount of direct solar radiation that reaches the roof with no obstructions and is absorbed by the roof, the second term represents the transmitted direct solar radiation through the tree absorbed by the roof, the third term is the indirect solar radiation that reaches the roof with no obstructions and is absorbed by the roof, and the fourth term is the indirect solar radiation transmitted through the tree canopy that is absorbed by the roof.

When the trees are taller than the building height, the amount of longwave radiation entering the street canyon is

$$
L^{c \uparrow}=L^{a \downarrow}\left\{1-f_{l}\left[1-T\left(0, h_{\mathrm{fa}}\right)\right]\right\}+L_{\mathrm{la} \uparrow}^{c},
$$

where $L_{\mathrm{la} \uparrow}^{c}$ is the amount of longwave radiation emitted from the tree canopy above the rooftop that enters the street canyon, defined by

$$
L_{\mathrm{la} \uparrow}^{c}=0.5 \sigma_{l}\left(L_{\mathrm{la} \uparrow}-L_{\mathrm{la} \uparrow}^{\mathrm{la}}\right),
$$

where $L_{\mathrm{la}} \uparrow$ is emitted from the tree canopy above the roof defined by

$$
L_{\mathrm{la} \uparrow}=\varepsilon_{l} \sigma_{l} T_{\mathrm{la}}^{4},
$$

and $L_{\mathrm{la} \uparrow}^{\mathrm{la}}$ is the amount of longwave radiation that is emitted from the tree that reaches the surface of other tree leaves above the roof height:

$$
L_{\mathrm{la} \uparrow}^{\mathrm{la}}=L_{\mathrm{la} \uparrow} f_{l}\left[1-T\left(0, h_{\mathrm{fa}}\right)\right],
$$

where $T_{\mathrm{la}}$ is the temperature of the leaves above the roof.

The longwave radiation flux when the trees are taller than the adjacent buildings is defined as

$$
\begin{aligned}
L_{r}^{\uparrow \downarrow}= & \varepsilon_{r}\left(L^{a \downarrow} F_{r \leftrightarrow a}+L^{a \downarrow}\left(1-F_{r \leftrightarrow a}\right)\left\{1-f_{l}\left[1-T\left(0, h_{\mathrm{fa}}\right)\right]\right\}\right. \\
& -\sigma T_{r}^{4}+0.25 \frac{w}{h_{\mathrm{fa}}} \sigma_{l}\left(L_{\mathrm{la} \uparrow}-L_{\mathrm{la} \uparrow}^{\mathrm{la}}\right) \\
& \left.\times\left(2-F_{\mathrm{lr} \leftrightarrow a}-F_{\mathrm{lr} \leftrightarrow r}\right) F_{r \leftrightarrow \mathrm{lr} \_ \text {side }}\right),
\end{aligned}
$$

where the first term is the amount of longwave radiation from the atmosphere that is not obstructed by the tree canopy and is absorbed by the roof, the second term is the amount of longwave radiation from aloft that is transmitted through the tree canopy and absorbed by the roof, the third term is the amount of longwave radiation emitted by the roof, and the fourth term is the amount of radiation that is emitted by the tree canopy and absorbed by the roof.

The longwave radiation flux in the tree canopy above the rooftop is the sum of the amount of radiation that is emitted from the road, grass/soil, building walls, building roof, tree canopy in and above the canyon, and atmosphere above the trees that is captured by the tree leaves minus the amount of radiation emitted from the tree canopy above rooftops, which is defined as 


$$
\begin{aligned}
L_{\mathrm{la}}^{\uparrow \downarrow}= & -L_{\mathrm{la} \uparrow}+L_{\mathrm{la} \uparrow}^{\mathrm{la}}+\frac{\varepsilon_{\mathrm{la}}}{\sigma_{l}} f_{l}\left[1-T\left(0, h_{\mathrm{fa}}\right)\right]\left\{L^{a \downarrow}+\sigma \varepsilon_{r} T_{r}^{4} F_{\mathrm{la} \leftrightarrow r}+f_{\mathrm{rd}} \sigma \varepsilon_{\mathrm{rd}} T_{\mathrm{rd}}^{4} \tau_{\mathrm{ga}} F_{a \leftrightarrow g}+f_{s} \sigma \varepsilon_{s} T_{s}^{4} \tau_{\mathrm{ga}} F_{a \leftrightarrow g}\right. \\
& +\sigma \varepsilon_{w} T_{w}^{4} \tau_{\mathrm{wa}} F_{a \leftrightarrow w}+L_{l \uparrow}^{a}+\left[f_{\mathrm{rd}}\left(1-\varepsilon_{\mathrm{rd}}\right) F_{a \leftrightarrow g} L_{l \uparrow}^{g}+f_{\mathrm{rd}}\left(1-\varepsilon_{\mathrm{rd}}\right) F_{a \leftrightarrow g} L^{c \downarrow} F_{g \leftrightarrow a} \tau_{\mathrm{ga}}\right. \\
& +\left(1-\varepsilon_{\mathrm{rd}}\right) F_{g \leftrightarrow w} \sigma \varepsilon_{w} T_{w}^{4} F_{g \leftrightarrow a} \tau_{\mathrm{wg}}+f_{s}\left(1-\varepsilon_{s}\right) F_{a \leftrightarrow g} L_{l \uparrow}^{g}+f_{s}\left(1-\varepsilon_{s}\right) F_{a \leftrightarrow g} L^{c \downarrow} F_{g \leftrightarrow a} \tau_{\mathrm{ga}} \\
& \left.+\left(1-\varepsilon_{s}\right) F_{g \leftrightarrow w} \sigma \varepsilon_{w} T_{w}^{4} F_{g \leftrightarrow a} \tau_{\mathrm{wg}}\right] \tau_{\mathrm{ga}}+\left[\left(1-\varepsilon_{w}\right) F_{a \leftrightarrow w} L_{l \uparrow}^{w}+\left(1-\varepsilon_{w}\right) F_{a \leftrightarrow w} L^{c \downarrow} F_{w \leftrightarrow a} \tau_{\mathrm{wa}}\right. \\
& \left.\left.+\left(1-\varepsilon_{w}\right) F_{a \leftrightarrow w} \sigma \varepsilon_{w} T_{w}^{4} F_{w \leftrightarrow w} \tau_{\mathrm{ww}}+\left(1-\varepsilon_{w}\right) F_{a \leftrightarrow w} f_{\mathrm{rd}} \sigma \varepsilon_{\mathrm{rd}} T_{\mathrm{rd}}^{4} F_{w \leftrightarrow g} \tau_{\mathrm{wg}}+\left(1-\varepsilon_{w}\right) F_{a \leftrightarrow w} f_{s} \sigma \varepsilon_{s} T_{s}^{4} F_{w \leftrightarrow g} \tau_{\mathrm{wg}}\right] \tau_{\mathrm{wa}}\right\} .
\end{aligned}
$$

\section{REFERENCES}

Akbari, H., 2002: Shade trees reduce building energy use and $\mathrm{CO}_{2}$ emissions from power plants. Environ. Pollut., 116, S119-S126.

—, D. M. Kurn, S. E. Bretz, and J. W. Hanford, 1997: Peak power and cooling energy savings of shade trees. Energy Build., 25, 139-148.

Annandale, J. G., N. Z. Jovanovic, G. S. Campbell, N. Du Sautoy, and P. Lobit, 2004: Two dimensional solar radiation interception model for hedgerow fruit trees. Agric. For. Meteor., 121, 207-225.

Arnfield, A. J., 2003: Two decades of urban climate research: A review of turbulence, exchanges of energy and water, and the urban heat island. Int. J. Climatol., 23, 1-26.

Atkinson, B. W., 2003: Numerical modeling of urban heat island intensity. Bound.-Layer Meteor., 109, 285-310.

Banta, R. M., and Coauthors, 1998: Daytime buildup and nighttime transport of urban ozone in the boundary layer during a stagnation episode. J. Geophys. Res., 103, 22 519-22 544.

— , and Coauthors, 2005: A bad air day in Houston. Bull. Amer. Meteor. Soc., 86, 657-669.

Bloomer, B. J., J. W. Stehr, C. A. Piety, R. J. Salawitch, and R. R. Dickerson, 2009: Observed relationships of ozone air pollution with temperature and emissions. Geophys. Res. Lett., 36, L09803, doi:10.1029/2009GL037308.

—, R. R. Dickerson, and K. Vinnikov, 2010: A chemical climatology and trend analysis of ozone and temperature over the eastern US. Atmos. Environ., 44, 2543-2551.

Bornstein, R., and Q. L. Lin, 2000: Urban heat islands and summertime convective thunderstorms in Atlanta: Three case studies. Atmos. Environ., 34, 507-516.

Boucouvala, D., and R. Bornstein, 2003: Analysis and transport patterns during an SCOS97-NARSTO episode. Atmos. Environ., 37 (Suppl. 2), 73-94.

Campbell, G. S., and J. M. Norman, 1998: An Introduction to Environmental Biophysics. 2nd ed. Springer, $286 \mathrm{pp}$.

Chen, F., and J. Dudhia, 2001: Coupling an advanced land surfacehydrology model with the Penn State-NCAR MM5 modeling system. Part I: Model implantation and sensitivity. Mon. Wea. Rev., 129, 569-585.

Cheng, Y. Y., and D. W. Byun, 2008: Application of high resolution land use and land cover data for atmospheric modeling in the Houston-Galveston metropolitan area, part I: Meteorological simulation results. Atmos. Environ., 42, 7795-7811.

Chicago Botanic Garden, cited 2011: Urban trees and shrubs-A guide to the selection of trees and shrubs in urban areas. [Available online at http://www.na.fs.fed.us/spfo/pubs/uf/uts/ index.htm.]

Darby, L. S., 2005: Cluster analysis of surface winds in Houston, Texas, and the impact of wind patterns on ozone. J. Appl. Meteor., 44, 1788-1806.
Dwyer, J. F., and D. J. Nowak, 2000: A national assessment of the urban forest: An overview. Proc. Society of American Foresters 1999 National Convention, Portland, OR, Society of American Foresters, 157-162.

Evtyugina, M. G., T. Nunes, C. Pio, and C. S. Costa, 2006: Photochemical pollution under sea breeze conditions, during summer, at the Portuguese West Coast. Atmos. Environ., 40, 6277-6293.

Grell, G. A., and D. Devenyi, 2002: A generalized approach to parameterizing convection combining ensemble and data assimilation techniques. Geophys. Res. Lett., 29, 1693, doi:10.1029/2002GL015311.

Heisler, G. M., 1986: Energy savings with trees. J. Arboric., 12,113-125. Imhoff, M. L., P. Zhang, R. E. Wolfe, and L. Bounoua, 2010: Remote sensing of the urban heat island effect across biomes in the continental USA. Remote Sens. Environ., 114, 504-513.

Jacob, D. J., and D. A. Winner, 2009: Effect of climate change on air quality. Atmos. Environ., 43, 51-63.

Janjić, Z. I., 1994: The step-mountain eta coordinate model: Further developments of the convection, viscous sublayer, and turbulence closure scheme. Mon. Wea. Rev., 122, 927-945.

Kunkel, K. E., S. A. Changnon, B. C. Reinke, and R. W. Arritt, 1996: The July 1995 heat wave in the Midwest: A climatic perspective and critical weather factors. Bull. Amer. Meteor. Soc., 77, 1507-1518.

Kusaka, H., and F. Kimura, 2004: Coupling a single-layer urban canopy model with a simple atmospheric model: Impact on urban heat island simulation for an idealized case. J. Meteor. Soc. Japan, 82, 67-80.

-, H. Kondo, Y. Kikegawa, and F. Kimura, 2001: A simple single layer urban canopy model for atmospheric models: Comparison with multi-layer and slab models. Bound.-Layer Meteor., 101, 329-258.

Landsberg, H. E., 1981: The Urban Climate. Academic Press, $288 \mathrm{pp}$.

Lee, S.-H., and S.-U. Park, 2008: A vegetated urban canopy model for meteorological and environmental modelling. Bound. Layer Meteor., 126, 73-102.

Lim, K.-S. S., and S.-Y. Hong, 2010: Development of an effective double-moment cloud microphysics scheme with prognostic cloud condensation nuclei $(\mathrm{CCN})$ for weather and climate models. Mon. Wea. Rev., 138, 1587-1612.

Loughner, C. P., D. J. Allen, K. E. Pickering, R. R. Dickerson, D.-L. Zhang, and Y.-X. Shou, 2011: Impact of the Chesapeake Bay breeze and fair-weather cumulus clouds on pollutant transport and transformation. Atmos. Environ., 24, 4060-4072.

Mass, C., D. Ovens, M. Albright, and K. Westrick, 2002: Does increasing horizontal resolution produce better forecasts? The results of two years of real-time numerical weather prediction in the Pacific Northwest. Bull. Amer. Meteor. Soc., 83, 407-430. 
McGinn, C., 1982: Microclimate and energy use in suburban tree canopies. Ph.D. dissertation, University of California, Davis, 299 pp.

Norman, J. M., and J. M. Welles, 1983: Radiative transfer in an array of canopies. Agron. J., 75, 481-488.

Nowak, D. J., D. E. Crane, and J. C. Stevens, 2006: Air pollution removal by urban trees and shrubs in the United States. Urban For. Urban Green., 4, 115-123.

Oke, T. R., 1973: City size and the urban heat island. Atmos. Environ., 7, 769-779.

- , and H. A. Cleugh, 1987: Urban heat-storage derived as energy balance residuals. Bound.-Layer Meteor., 39, 233-245.

Skamarock, W. C., and Coauthors, 2008: A description of the Advanced Research WRF version 3. NCAR Tech. Note NCAR/TN-475+STR, 125 pp.

Souch, C. A., and C. Souch, 1993: The effect of trees on summertime below canopy urban climates: A case study, Bloomington, Indiana. J. Arboric., 19, 303-312.

Taha, H., 1995: Modeling impacts of increased urban vegetation on ozone air quality in the south coast air basin. Atmos. Environ., 30, 3423-3430.

- S. Douglas, and J. Haney, 1997: Mesoscale meteorological and air quality impacts of increased urban albedo and vegetation. Energy Build., 25, 169-177.

Tai, A. P. K., L. J. Mickley, and D. J. Jacob, 2010: Correlations between fine particulate matter (PM2.5) and meteorological variables in the United States: Implications for the sensitivity of PM2.5 to climate change. Atmos. Environ., 44, 39763984.

TreesNY and CENYC, cited 2011: Citizen Pruners, and USDA Forest Service Northeastern, Research Station, Neighborhood Tree Survey-Summary by tree species. [Available online at http://www.oasisnyc.net/trees/downloads/sum-by-species.pdf.]

Vukovich, J., and T. Pierce, 2002: The implementation of BEIS-3 within the SMOKE modeling framework. 11th Int. Emissions Inventory Conf.: Emissions Inventories-Partnering for the Future, Research Triangle Park, NC, Environmental Protection Agency. [Available online at http://www.epa.gov/ttn/ chief/conference/ei11/modeling/vukovich.pdf.]

Weaver, C. P., and Coauthors, 2009: A preliminary synthesis of modeled climate change impacts on U.S. regional ozone concentrations. Bull. Amer. Meteor. Soc., 90, 1843-1863.

Yegorova, E. A., D. J. Allen, C. P. Loughner, K. E. Pickering, Y. E. Yorks, and R. R. Dickerson, 2011: Characterization of an eastern U.S. severe air pollution episode using WRF/chem. J. Geophys. Res., 116, D17306, doi:10.1029/2010JD015054.

Zhang, D.-L., Y.-X. Shou, and R. R. Dickerson, 2009: Upstream urbanization exacerbates urban heat island effects. Geophys. Res. Lett., 36, L24401, doi:10.1029/2009GL041082.

, — - _ - and F. Chen, 2011: Impact of upstream urbanization on the urban heat island effects along the WashingtonBaltimore corridor. J. Appl. Meteor. Climatol., 50, 2012-2029. 